\title{
Does maternal arachidonic acid influence the neurodevelopmental effects of docosahexaenoic acid?
}

\section{Sanjay Basak ${ }^{1}$, Rahul Mallick ${ }^{2}$, Antara Banerjee ${ }^{3}$, Surajit Pathak ${ }^{3}$, Asim K. Duttaroy $^{*}$}

${ }^{1}$ Molecular Biology Division, ICMR-National Institute of Nutrition, Indian Council of Medical Research, India

\section{${ }^{2}$ A.I. Virtanen Institute for Molecular Sciences, University of Eastern Finland, Finland}

${ }^{3}$ Department of Medical Biotechnology, Faculty of Allied Health Sciences, Chettinad Academy of Research and Education (CARE), Chettinad Hospital and Research Institute (CHRI), Kelambakkam, Chennai 603 103, India

\author{
${ }^{4}$ Department of Nutrition \\ Institute of Basic Medical Sciences \\ Faculty of Medicine \\ University of Oslo, \\ Oslo, Norway
}

\section{${ }^{*}$ Corresponding Author}

Professor Asim K. Duttaroy

Department of Nutrition, Institute of Basic Medical Sciences,

Faculty of Medicine,

University of Oslo,

Oslo, Norway

Email: a.k.duttaroy@medisin.uio.no

Tel: +4722 821547 


\begin{abstract}
During the last trimester of gestation and for the first 18 months after birth, docosahexaenoic acid,22:6n-3 (DHA) and arachidonic acid,20:4n-6 (ARA) deposited within the cerebral cortex at a rapid rate. The mode of action of these two fatty acids and their derivatives at different structural-function and signaling pathways levels in the brain have been continuously emanating. These fatty acids are also involved in various brain developmental processes; however, their mechanisms of action are not yet well known. Recent data suggest that there may be a need for a balanced proportion of ARA and DHA in infant formula due to their complementary benefits. This review describes the importance of maternal preferential transfer of ARA and DHA to support the infant's optimal brain development and growth and functional roles in the brain.
\end{abstract}

Keywords: Arachidonic acid,20:4n-6; Brain; Docosahexaenoic acid, 22:6n-3; Fetus; Maternal diet; Cognitive; Infants; Neurodevelopment; Neurogenesis

\title{
Abbreviations:
}

ARA: Arachidonic acid; AD: Alzheimer's disease; ADHD: Attention deficit hyperactivity disorder; ALA: $\alpha$-linolenic acid, 18:3n-3; COX: Cyclooxygenase; DHA: Docosahexaenoic acid,22:6n-3; EPA: Eicosapentaenoic acid,20:5n-3; LCPUFAs: Longchain polyunsaturated fatty acids; LOX: Lipoxygenases; NO: Nitric oxide; PUFAs: Polyunsaturated fatty acids; 


\section{Introduction}

The neurodevelopmental process involves a complex interplay between nutrients, genes, and environmental factors that result in optimal growth, development, and maturation of the brain. The development of the brain in utero critically depends on the maternal supply of several components for its well-regulated structuraldevelopmental process characterized by specific, well-defined developmental periods, growth, cellular signaling system, and maturation. During the brain growth spurt, neurodevelopment is particularly vulnerable to nutritional deficiencies [1].

Docosahexaenoic acid,22:6n-3 (DHA), and arachidonic acid,20:4n-6 (ARA) are important nutrients required for fetal brain growth and development. The accumulation of DHA in the fetal brain predominantly occurs in the third trimester of a human pregnancy. It continues at an accelerated rate up to the second year of life. Since de novo synthesis of DHA is low in a growing fetus, DHA intake contributes a significant share for brain development. Maternal DHA and ARA are accumulated rapidly within the cerebral cortex region during the last trimester of pregnancy and postnatal 18 months [2-4]. The dietary balance of DHA and ARA intake and their interactions are essential in brain development. Several experimental studies suggested a crucial involvement of long-chain polyunsaturated fatty acids (LCPUFAs), especially DHA and ARA, in membrane formation and various roles of their metabolites, production of eicosanoids, and their influence on the depressionand anxiety-related behaviors. Multiple trials have found that higher plasma or 
erythrocyte DHA levels positively correlate with infant neurocognitive outcomes[510].

The preferential transfer of maternal LCPUFAs such as DHA and ARA by the placenta to fetal circulation and its mechanisms are reviewed extensively [11,12]. LCPUFAs contents in human milk are also regulated the amount of DHA and ARA transferred to the infant during breastfeeding [13]. Thus, the high levels of DHA in the brain are achieved during early life and are maintained throughout life. DHA accretion to the brain continues into childhood, and the incorporation of DHA is still high despite its reduced accumulation rate. However, this phenomenon may depend on an optimal maternal dietary intake of DHA from the supplement or marine fish [14]. In the central nervous system (CNS), the proportion of DHA with other membrane fatty acids increases as the brain size increases.

DHA and ARA are predominant LPCUFAs in the CNS and play essential roles in fetal and infant neurodevelopment. The increase in the proportion of these fatty acids continues for the second year of life. Synaptic membrane phospholipids contain DHA and ARA and are released as free fatty acids (FFAs) by activated phospholipase $\mathrm{A}_{2}$ $\left(\mathrm{PLA}_{2}\right)$ and are converted to different bioactive metabolites during ischemia seizure activity, inflammation, and other types of brain disorders. DHA has significant neurobiochemical roles in ion channel and receptor functions, the release of neurotransmitters, synaptic plasticity, and gene expression in the neurons. Figure-1 describes the putative roles of DHA in neural membranes. In addition to early 
Figure-1 DHA modulates several aspects of structural and functional activities of neuronal membrane

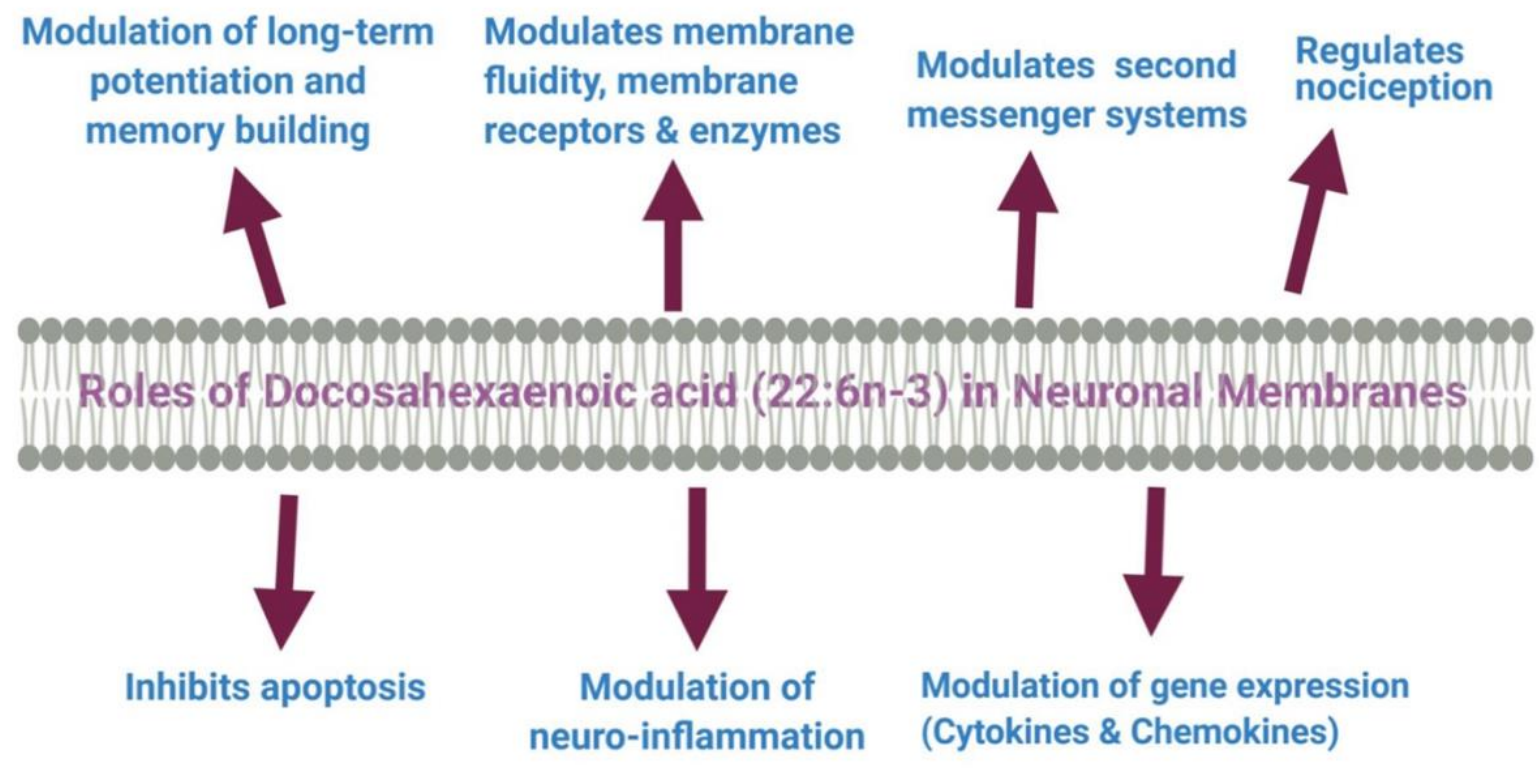

development, DHA's requirement is being recognized in childhood and adult life, suggest its roles in delaying cognitive decline and modulating psychiatric disorders [15]. In fact, DHA supplementation may ameliorate neurodegeneration and modulate behavioral symptoms in major neuropsychiatric disorders such as dementia, schizophrenia, and depression in adults [16]. Human breast milk containing higher n3 and n-6 LCPUFAs was associated with decreased infant despair and distress [17]. The impact of n-3 PUFAs in human milk in influencing infant mood or anxiety is still not clearly established since cortisol levels in milk are also associated with infant temperament[18]. Moreover, the variation in the fatty acids composition of mothers' 
milk may play an essential role in the outcome of offspring mental status and overall health.

Although n-3 LCPUFAs supplementation is thought to be beneficial in preventing and treating major depression, bipolar disorder, and anxiety disorders in adults [19], much less is known about how the imbalance of the n-3 LCPUFAs levels impact the mood and behavior of infants in later life. Plasma DHA levels are inversely correlated with depressive symptoms in infants and adolescents with bipolar disorder[20]. Studies in experimental models suggested that early exposure to n-3 fatty acids had a lasting effect on temperament and behavioral phenotypes of offspring [21]. Interventional studies in adults showed an association between the n-3 PUFAs status with improved mood and mental health [21,22]. Maternal n-3 PUFA deficiency during pregnancy was associated with impaired brain development in offspring [23] and defective neuroblast migration [24]. The deficiency of n-3 LCPUFAs during development causes hypomyelination in the brain, resulting in mood and anxiety disorders[22,25]. Consuming a diet containing a high amount of n-3 fatty acids during pregnancy protected infants against the detrimental effects of maternal stress [26].

Though precise molecular mechanisms are not well defined, DHA and its bioactive derivatives play various essential functions in the brain[12,27,28]. High DHA levels in the phospholipids of synaptic membranes provide membrane flexibility and improve the efficiency of protein-protein interaction necessary for signal transduction[27]. Different aspects of metabolism, structure-function of the brain depend on optimum ARA and DHA levels and interactions between their 
metabolites[29]. Furthermore, several human brain diseases, such as Alzheimer's and bipolar disorders, involve disturbed n-3 and n-6 LCPUFA uptake and metabolism. Therefore, understanding the dynamics of maternal DHA and ARA uptakes and their metabolism in the developing brain may be important determinants for managing brain disorders. An additional neuroprotective mechanism may involve bioactive molecules derived from DHA and ARA, which are also involved in several cellular neuronal processes. These bioactive fatty acid derivatives modify the functions of several genes in the brain by acting as ligands for transcription factors involved in critical brain functions, including signal transduction and synaptic plasticity.

This review summarizes the effects of the maternal interplay of DHA and ARA transfer on infant brain development, their complementarity, the structure-function relationship, and their mechanisms of action in the brain.

\section{Maternal delivery of DHA to the developing brain}

Maternally derived DHA plays a critical role in the brain development of infants [30,31]. DHA deposition in the brain takes place in intrauterine and in the lactation period [32]. Accretion of DHA in the fetal brain is the highest in the third trimester of pregnancy [33]. DHA incorporation in the neuronal membrane in early life solely depends on placental transfer [11], breastfeeding, and endogenous synthesis of DHA [34,35]. Maternal dietary intakes of fatty acids influence the fatty acid composition of breast milk and plasma levels of lactating women and their infants[36]. 
A robust linear relationship between maternal DHA level and umbilical cord plasma phospholipid contents was reported [37].

The growing fetus depends on the placental supply of maternal DHA due to the limited endogenous synthesis of DHA [11]. DHA also has a role in the early placentation process and development of the fetal brain during the last trimester of pregnancy[38-40]. The high-affinity placental plasma membrane, fatty acid-binding protein (p-FABPpm), is involved in DHA and ARA's maternal transport to the fetus $[12,35,41]$. Since the rapid deposition of DHA into the brain occurs during the last trimester of pregnancy and subsequently in lactation, the maternal DHA status must be maintained well during the critical time of brain development. The dietary intake and maternal stores of DHA are the determinants of infant blood DHA concentrations at birth[42]. Blood LCPUFA in breast-fed infants remain higher than maternal levels for some time postnatally[43,44]. The preferential postnatal accumulation of LCPUFAs in infant brain tissues is mediated via breastmilk. Dietary supplementation of DHA to pregnant and nursing mothers dose-dependently increases the DHA level in breast milk, which causes higher tissue accretion of DHA in breastfed infants with improved outcomes of mental performance[45-47].

Based on established guidelines, it is emphasized that maternal dietary DHA requirements should be increased during pregnancy and lactation. Precisely, a minimum of 200mg of DHA per day is recommended during these periods [48]. In both full-term and preterm populations, the evidence is compelling that breastfeeding is vital for an infant's neurodevelopment. 
Children's intelligence quotient (I.Q) was increased by 0.8 to 1.8 points when their mothers were supplemented with DHA for a more extended period from pregnancy to lactation period and beyond [49,50]. Worldwide, mean levels of DHA and ARA in breast milk are found $0.37 \%$ and $0.55 \%$ of total fatty acids, respectively. Many prospective observational studies indicated that breastfed infants had a significant neurocognitive advantage compared with formula-fed infants [5,51,52], possibly due to the higher incorporation of DHA and ARA in breast milk relative to formula milk. The association between breastfeeding and child IQ concerning FADS2 genetic profile, specifically in SNP rs174575b, was observed [53]. Breastfed infants with rs174575 Cdominant carriers achieved higher scores on standardized IQ tests than non-breastfed C-carriers infants. However, observational data are confounded by the heterogeneous composition of breast milk, environmental factors that influence the infant's mental development.

\section{The fatty acid uptake system of the brain}

The de novo synthesis of DHA in the brain is almost non-existent, and therefore it must be imported from the circulation across the blood-brain barrier (BBB)[33]. The BBB comprises capillary endothelial cells connected with tight junctions, astrocytic end-foot processes, pericytes, and neurons[54]. The endothelial cells offer highly selective permeability in BBB by their specialized tight junction function. Thus, BBB is provided with a neuronal system immune-privileged environment permitting only small molecules into the brain. 
The passive diffusion of non-esterified DHA or ARA through endothelial cells' membrane seems one of the major entries of these fatty acids within the BBB [55-61]. Free fatty acids (FFAs) are transported into the cytosol with the help of cell membraneand cytoplasmic fatty acid-binding proteins (FABPs)[12]. There are four classes of fatty acid transport proteins present in the adult brain: Fatty acid translocase (FAT/CD36), plasma membrane-fatty acid-binding proteins (FABPpm), fatty acid transport proteins (FATPs), and cytosolic FABPs [35,62,63]. Additionally, another transporter, Mfsd2a (major facilitator superfamily domain-containing protein $2 \mathrm{~A}$ ), is present in $\mathrm{BBB}[12]$. Mfsd2a transports lysophosphatidylcholine (LPC)-DHA, but not unesterified

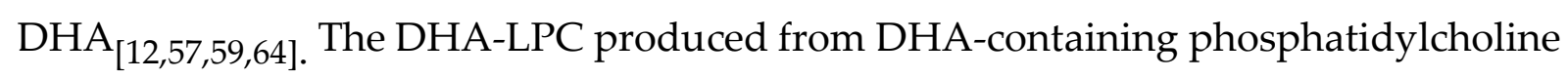
when acted upon by PLA1. A sterol regulatory element-binding protein regulates the activity of Mfsd2a to maintain a balance between de novo lipogenesis and exogenous uptake of LPC-DHA. The brain of the Mfsd2a-deficient mice had significantly reduced DHA levels and experienced loss of neurons in the hippocampus and cerebellum. The mice later developed microcephaly with severe cognitive deficits and anxiety. Altered plasma levels of Mfsd2a during pregnancy influence placental transport of DHA and neurodevelopment in utero [65]. Maternal blood levels of Mfsd2a in the third trimester were inversely correlated to DHA-LPC in maternal plasma [65]. DHA or DHA-LPC is taken up by the endothelial cells via FAT/CD36, FATPs, or Mfsd2a. Plasma albumin binds both unesterified DHA and DHA-LPC. 
Like LPC-DHA, accretion of ARA to the brain from ARA-containing lysophospholipids is six-fold more efficient than for unesterified ARA[66]. The brain relies on different transport systems for shuttling the varied forms of the metabolized DHA across the BBB. Active pathways of DHA and ARA incorporation into the brain include members of the FABP family. In human brain microvessel endothelial cells, FAT/CD36 and FATP-1, FATP4 also transport fatty acids across the monolayer[63]. Although, DHA incorporation into brain phospholipids was not affected in CD36-/mice indicating this transporter may not involve in the transport of DHA.

FABPs involve in the FFA uptake and transport to various intracellular compartments of a cell $[63,67]$. Expression of various FABP genes occurs at different developmental stages of the brain. Several transcription factors are involved in the developmental regulation of FABP gene expression. FABP3 is expressed in the brain after birth, and its level of expression levels increases until adulthood[68]. FABP4 is mainly expressed in grade IV astrocytomas and normal brain tissue[69]. Whereas FABP5 is expressed in the mid-term embryonic rat brain and reaches its peak at birth, then gradually decreases in postnatal life[68]. FABP7 is expressed mainly in radial glial cells at the early stages of brain development[68,70]. The level of FABP7 expression decreases starkly in the neonate and adult brain [68]. FABP7 plays a role in the establishment of the radial glial fiber system[70]. Moreover, FABP7 has been suggested to be associated with decreased survival of glioblastoma patients [71-73]. 
FABPs have broad binding specificity, including the binding affinity for longchain fatty acids ( $\geq$ c16), eicosanoids, bile salts, and PPARs[35,74]. Both FABP3 and FABP4 bind ARA with high affinity $[75,76]$ while FABP5 preferentially binds long-chain saturated fatty acids $(c \geq 16)$ [77]. FABP7 binds both DHA and ARA but with 4-fold more affinity for DHA [78], indicating that DHA may be a preferred ligand for FABP7. Although FABP7, FABP5, and FABP3 can also bind different types of fatty acids[77,79].

FABP3, FABP5, and FABP7 are involved in both developing and adult brains $[74,80]$. Functional studies have revealed various roles for FABPs in brain development, including the generation of neuronal and/or glial cells, differentiation, neuronal cell migration, and axis patterning. Like DHA, FABP7 increases the proliferation of neural stem cells and neural progenitor cells and differentiates into mature neurons both in vitro and in vivo[81,82].

FABPs are multi-functional proteins, and complex signaling networks and transcription factors regulate their expression. FABPs are major downstream effectors of the Reelin-Dab1/Notch pathway that involves neuron-glia crosstalk during brain development. Since LCPUFAs and several FABPs are involved in brain development and function, it is important to further elucidate their roles in brain disorders' pathogenesis.

Mental retardation is a typical phenotypic feature of Down syndrome patients. As FABPs are involved in developing, establishing, and maintaining the central 
nervous system, it is reasonable to propose that FABPs may be implicated in the pathogenesis of Down syndrome. FABP7 is overexpressed in Down syndrome adult [83] and fetal brains[84] whereas FABP3 is significantly decreased in Down syndrome adult brains [83]. Furthermore, FABP7 upregulation correlates with PKNOX1 genedosage imbalance in the brains of Down syndrome patientsPKNOX1 is a POU domain protein that may directly control FABP7 expression by interacting with the $\mathrm{Pbx} / \mathrm{POU}$ binding element of the FABP7 promoter [84]. Human FABP7 mRNA levels were significantly upregulated in the postmortem brains of schizophrenia patients. A correlation between an SNP variant within the second exon of human FABP7 and schizophrenia pathology was observed [85]. Impairment of prepulse inhibition (PPI) occurs in many brain disorders such as Alzheimer's disease, autism, bipolar disorders, Tourette syndrome, and schizophrenia[86]. The association between FABP7 and PPI status suggests roles of the FABP7 gene in the pathology of PPI-mediated neuropsychiatric and/or neurodegenerative diseases. The association of FABP3 and FABP5 with several neurodegenerative diseases is also reported $[87,88]$.

\section{Structural and functional roles of DHA in the human brain}

The brain is known as the body's fattiest organ, containing phospholipids around $2 / 3$ of its weight. The fatty acid is used for energy requirements in the brain. Brain harness $20 \%$ of total energy from $\beta$-oxidation of fatty acids in the mitochondria of astrocytes. The CNS is highly enriched in DHA and ARA, participating in several crucial processes in neuronal membranes with important structural, functional, and 
signaling roles. The presence of DHA on the membrane influences neuronal information transmission, signal transduction velocity, and interaction with ion channels or receptor proteins and their activity [89]. DHA is also predominantly present in cortical gray matter, representing approximately $15 \%$ of total fatty acids in the adult human prefrontal cortex. As a crucial structural component of the brain, DHA comprises the regions of the cerebral cortex and synaptic membrane. Neuronal membranes have approximately 50\% DHA [37]. DHA is vital for hippocampal and cortical neurogenesis, neuronal migration, and outgrowth [90-92]. Therefore, the maintenance of DHA status is crucial for optimal brain function.

The brain fatty acid levels, mostly LCPUFAs are maintained via different mechanisms, as described above. Thus, circulating plasma DHA is positively related to cognitive abilities during aging and is inversely associated with decline in cognitive function. Being an integral component of cell membrane phospholipid, DHA contributes to maintaining optimal fluidity and lipid raft assembly in the membranes. DHA influences the membrane electrical and antigenic signals of the cells. DHA also may halt cell death by stimulating cell-cycle exit in neuro-progenitor cells [92,93]. DHA is also involved in monoaminergic and cholinergic systems during brain development processes [45,94-96]. DHA supply during the fetal brain development in utero has a long-term effect on serotonergic and dopaminergic systems [95,97]. Several studies emphasized the long-term critical impact on brain development due to inadequate DHA supplies to the fetus during pregnancy. DHA stimulates neurite outgrowth in cell culture systems. Neurite outgrowth is an important process in the developing 
nervous system and also in the regeneration of nerves. The ALA (the precursor of DHA) -restricted diet decreased neurogenesis in rat dams' fetal brains, possibly due to lack of DHA[98]. DHA influences gene expression, neurotransmission and protects the brain from oxidative stress during development [99]. DHA is an essential factor for neurogenesis, phospholipid synthesis, and turnover [92,100,101]. Although it should be acknowledged that DHA plays a critical role in developing the brain, the role of dietary DHA in human brain development is still not well understood.

Again, DHA can act as a ligand for peroxisome proliferator-activated receptorgamma (PPAR $\gamma$ ) and retinoid X receptor (RXR). RXR plays a vital role in embryonic neurogenesis, neuronal plasticity, and catecholaminergic neuron differentiation along with retinoic acid receptors. RXR is highly expressed in the hippocampus [102,103]. PPAR $\gamma$-RXR heterodimer modulates early brain development by regulating transcription genes [102,104].

DHA also protects the developing brain from peroxidative damage of lipids and proteins [105-107]. DHA and EPA were reported as suppressors of angiogenesis in cancer cells, but they stimulate angiogenesis in the placenta [38]. However, DHA and DHA-LPC may act pro-angiogenic and anti-angiogenic depending on the concentration and microenvironments [108]. Clinical and biochemical studies demonstrated that DHA is involved in brain development and critical brain functions $[49,109,110]$. Several epidemiological data support an inverse association of low habitual dietary intake of DHA and a higher risk of brain diseases [4,111,112]. A diet containing high amounts of n-3 fats and/or a lower amount of n-6 fats was strongly associated 
with the lower incidence of Alzheimer's disease and other brain diseases [113-116]. Intake of DHA improves attention deficit hyperactivity disorder (ADHD), bipolar disorder, schizophrenia, impulsive behavior, and other brain disorders [15,115,117].

Nevertheless, the data of intervention studies with DHA supplements are conflicting, despite many such studies demonstrated an apparent benefit of DHA intake in brain function. Several studies failed to show reproducibly that the absence of DHA and its metabolites are involved in various adult brain diseases. More welldesigned clinical trials considering background diets and genetic makeup are needed for definitive conclusions.

\section{Roles of DHA and its metabolites in the brain}

DHA and its metabolites are vital for functional brain development of the fetus in utero and infants and healthy brain function in adults. DHA and its metabolites play significant roles in cellular and biological functions. Oxidation of DHA by lipoxygenases produces several types of oxylipins that regulate various biochemical processes of the brain. DHA is thought to be an essential nutrient required throughout the life cycle to maintain overall brain health. As a polyunsaturated n-3 fatty acids family member, DHA is an important and indispensable fatty acid for human health that can be sourced from marine fish and oils[27]. Also consumed plant oil sourced n3 fatty acid, $\alpha$-linolenic acid,18;3n-3 (ALA) or marine sourced eicosapentaenoic acid,20:5n-3 (EPA) can be converted into DHA in a small amount. DHA levels are decreased in apoptotic neurological disorders, including Alzheimer's and Parkinson's 
diseases. Dietary DHA deficiency may lead to inflammatory conditions, cognitive disorders, insufficient neurogenesis, defective neurotransmitter metabolism, insufficient brain growth, and development[27,33].

DHA's mode of action and its derivatives at both cellular and molecular levels in the brain are emerging. DHA stimulates membrane-associated G-protein-coupled receptor (GPCR) 120 mediated gene activation to promote anti-inflammatory activities [118]. DHA also activates PPARs and upregulates the expression of genes responsible for increasing insulin sensitivity and reducing plasma triglyceride level and inflammation. [37]. DHA and its metabolites' signaling pathways are involved in neurogenesis, anti-nociceptive effects, anti-apoptotic effects, the plasticity of the synapse, $\mathrm{Ca}^{2+}$ homeostasis in the brain, and nigrostriatal activities[119]. DHA itself and its metabolites have a broad spectrum of actions at different levels and sites in the brain [119-121]. Figure-2 shows the DHA and EPA metabolites and their function in the brain.

\section{Eicosapentaenoic acid, 20:5n-3 Docosahexaenoic acid, 22:6n-3}

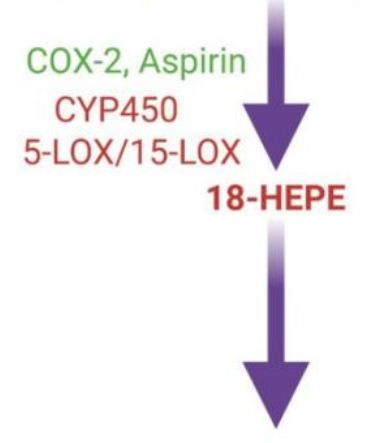

RESOLVINS E-series

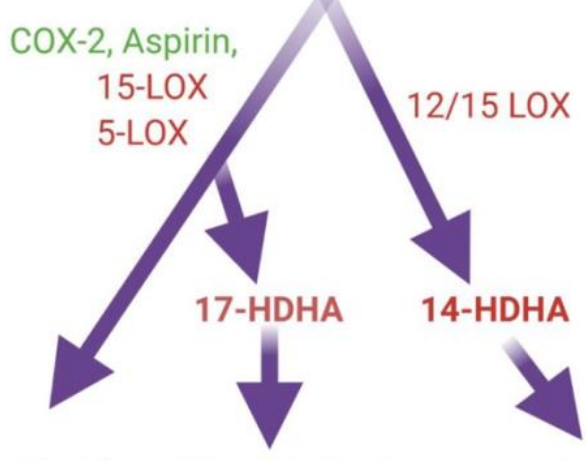

PROTECTINS

RESOLVINS D-series

MARESINS

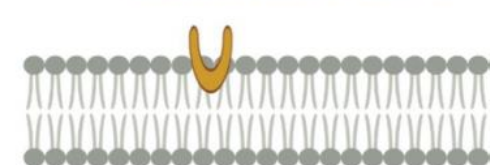

BLT1/ ChemR23 


\section{Figure -2 Metabolites of EPA and DHA, and their membrane receptors}

DHA is converted into maresin 1(MaR1), neuroprotectin D1(NPD1), and resolvins by human 12-LOX, 15-LOX, and CYP or aspirin-treated COX-2 enzymatically. These metabolites have multiple functions in the brain, which have been mentioned in the upper and lower boxes. DHA is metabolized by the P450 system, cyclooxygenase, and lipoxygenase enzymes under different metabolic conditions. 14-HDHA: 14-hydroxy-docosahexaenoic acid; 17-HDHA: 17-hydroxydocosahexaenoic acid; 18-HEPE: 18-hydroxy-eicosapentaenoic acid; LG R6 : G protein-coupled receptor 6;

ALX/Fpr2: N-formyl peptide receptor 2; BLT1: leukotriene B4 receptor; COX-2: cyclooxygenases; DHA: docosahexaenoic acid; EPA: eicosapentaenoic acid; GPR32/37: G protein-coupled receptor 32/37; LC-PUFAs: long-chain polyunsaturated fatty acids; LOX: lipoxygenases.

DHA-derived specialized pro-resolving mediators (SPMs) such as DHA epoxides, oxo-derivatives (EFOX) of DHA, neuroprostanes, ethanolamines, acylglycerols, docosahexaenoyl amides of amino acids or neurotransmitters, and branched DHA esters of hydroxy fatty acids [122,123]. Also, epoxydocosapentaenoic acids (EDPs) and 22-hydroxydocosahexaenoic acids (22-HDoHEs) are produced from DHA [124,125]. DHA is mainly metabolized by enzymes such as 5-, 12- and 15-lipoxygenases (LOX), COX-2, and cytochrome P450 (CYP). As the most demanding by-products of DHA, resolvins are formed by either LOX15 or CYP or aspirin-treated COX-2 activity [126]. The LOX15-derived resolvins are homologous to CYP-, or aspirin-treated COX-2derived resolvins [126]. As the potential inflammation resolution mediators, resolvins acts through a different kind of G-protein coupled receptors (GPRs)[28,127]. Both 
resolvin D1 and aspirin-triggered resolvin D1 improve brain functions and impede neuronal death by down-regulating several factors such as NFkB, TLR4, CD200, and IL6R [128,129]. Even they induce remote functional recovery after brain damage [128]. Both resolvin D2 and aspirin-triggered resolvin D2 protect from cerebral ischemic injury via phosphorylation ERK1/2. Subsequently, this pathway stimulates nNOS or eNOS to inhibit neuronal cell death and maintain BBB integrity by increasing zonula occludens-1 [130]. Resolvin D3, resolvin D5, aspirin-triggered COX-2 -derived resolvin D3, and aspirin-triggered resolvin D5 halt the neuroinflammation [131,132]. However, the functions of other resolvins are still a mystery. Maresin (MaR), the antiinflammatory pro-resolving mediator, is produced from DHA in macrophages during inflammation, healing, and regeneration process [133-135]. MaR1 is predominant among other maresins. MaR1 decreases $\mathrm{LTB}_{4}$ synthesis and stimulates phagocytosis at the site of inflammation [136-138]. MaR1 enhances tissue repair by stimulating stem cell differentiation and plays an analgesic role through TRPV1-mediated response blockage $[137,139]$. MaR1 involves neurocognitive functions by regulating infiltration of macrophages, regulating NF- $\mathrm{B}$ signaling, oxidative stress, and cytokine release. Maresin 1 reduces neuroinflammation perioperative neurodegenerative disorders in an animal model [140]. MaR1 significantly affects the post-spinal cord injury model [141,142].

Another SPM, Neuroprotectin D1(NPD1), derived from DHA, improves cell survival and cell repair in brain disorders [143]. Like MaR1, NPD1 also possesses antiinflammatory and neuroprotective activities [144]. In response to neuroinflammation, 
NPD1 is produced from endogenous DHA in the retina and brain $[145,146]$. Besides antiviral protection, NPD1 helps in neurocognitive functions [147-149]. NDP1 blocks the progression of Alzheimer's disease by stimulating the expression of PPAR $\gamma$, amyloid precursor protein- $\alpha$, and reducing the $\beta$-amyloid precursor protein [149].

Anti-inflammatory activities of EFOX and neuroprostanes protect neuroinflammation in various diseases, such as Parkinson's disease and Alzheimer's disease [150-152]. Another DHA derivative, docosahexaenoyl ethanolamide, improves mood, pain, inflammation status, hunger, and glucose uptake by the brain endocannabinoid system [153-158]. The function of DHA metabolites is summarized in Table-1.

Table 1: Functions of DHA and ARA metabolites

\begin{tabular}{|c|c|c|}
\hline Types of metabolites & Name of metabolites & Effects \\
\hline \multirow{6}{*}{ Oxygenated metabolites } & Maresins & $\begin{array}{l}\text { Resolution of inflammation, wound } \\
\text { healing, analgesic actions }\end{array}$ \\
\hline & Protectins & $\begin{array}{l}\text { Resolution of inflammation, } \\
\text { neuroprotection }\end{array}$ \\
\hline & Resolvins & $\begin{array}{l}\text { Resolution of inflammation and } \\
\text { wound healing }\end{array}$ \\
\hline & $\begin{array}{l}\text { Electrophilic } \\
\text { derivatives (EFOX) oxo- } \\
\text { DHA }\end{array}$ & $\begin{array}{l}\text { Anti-inflammatory, anti-proliferative } \\
\text { effects }\end{array}$ \\
\hline & Epoxides & Anti-hypertensive, analgesic actions \\
\hline & Neuroprostanes & Cardioprotection wound healing \\
\hline \multirow{3}{*}{ DHA conjugates } & $\begin{array}{l}\text { Ethanolamines and } \\
\text { glycerol esters }\end{array}$ & $\begin{array}{l}\text { Neural development, } \\
\text { immunomodulation, metabolic effects }\end{array}$ \\
\hline & $\begin{array}{l}\text { Branched fatty acid esters } \\
\text { of hydroxy fatty acids } \\
\text { (FAHFA) }\end{array}$ & $\begin{array}{l}\text { Immunomodulation, resolution of } \\
\text { inflammation }\end{array}$ \\
\hline & $\mathrm{N}$-acyl amides & $\begin{array}{l}\text { Metabolic regulation, neuroprotection, } \\
\text { neurotransmission }\end{array}$ \\
\hline ARA metabolites & Lipoxins A4 & $\begin{array}{l}\text { Lowers neuroinflammation } \\
\text { reducing microglial activation }\end{array}$ \\
\hline
\end{tabular}




\begin{tabular}{|l|l|l|}
\hline & & \\
\hline & Lipoxins B4 & $\begin{array}{l}\text { Lipoxins B4 promote neuroprotection } \\
\text { from acute and chronic injury }\end{array}$ \\
\hline
\end{tabular}

DHA glyceryl ester regulates the intake of food and neuroinflammation, similarly as docosahexaenoyl ethanolamide does use the endocannabinoid system $[159,160]$. The endocannabinoid system plays an integral part in memory, cognition, and pain perception [161,162]. DHA conjugates via cannabinoid receptors reduce neuroinflammation and improve neurogenesis [163,164]. Dietary intervention with DHA maintained healthy brain function, preventing stress, depression, and reduces brain degenerative disorders $[165,166]$. DHA supplementation may play a substantial role in the mental health of post-natal life. Nutrients can mediate stress-induced hormone production via the hypothalamus-pituitary-adrenal axis $[167,168]$. Since fatty acids are an integral part of the brain membranes, consequently, the fatty acid status may have a relationship with stress $[169,170]$. DHA also has a significant role in brain development to alleviate short-term stress, preventing anxiety and stress in later life $[123,171]$

DHA improves various psychiatric disorders such as schizophrenia, mood and anxiety disorders, obsessive-compulsive disorder, ADHD, autism, aggression, hostility and impulsivity, borderline personality disorder, substance abuse, and anorexia nervosa [172]. There is strong evidence that the consumption of marine fishes reduces depression [173].

Higher marine fish consumption improves cognitive function [174]. DHA has a significant role in reducing the risk of dementia [175]. Neuroinflammation in 
Alzheimer's disease can be reduced by DHA supplementation [176,177]. DHA-derived anti-inflammatory eicosanoids, neuroprotection prevent Alzheimer's disease pathogenesis [178]. DHA may modulate the metabolism of cholesterol and apolipoprotein E, lipid raft assembly, cell signaling system in Alzheimer's disease $[179,180]$. DHA protects neuronal brain function by reducing NO production, calcium influx, and apoptosis while activating antioxidant enzymes such as glutathione peroxidase and glutathione reductase [181]. The second most prevalent neurodegenerative disease, Parkinson's disease, can be prevented by DHA's neuroprotective role [181].

The mild symptoms of ADHD are corrected with DHA supplementation [182]. DHA was also shown to improve depressive symptoms of bipolar disorder by increasing $\mathrm{N}$-acetyl-aspartate brain levels without affecting mania [172]. Even IQ outcomes in children and cognitive function in the aging brain are improved by DHA supplementation [31,183].

Interestingly the studies have been reported that EPA, in association with DHA, improves cognitive function. Membrane DHA influences lipid rafting, signal transduction, and neurotransmission $[95,184,185]$. On the other hand, gene expression and ion channel activities are related to unesterified DHA properties [186-188].

Surprisingly, DHA influences brain functions and protects from different brain tumors such as astrocytoma and glioma by binding to the FABP, resulting in the activation of transcription factor PPAR $\gamma$ to the nucleus reduce cell migration, growth arrest, and apoptosis of tumor cells [189]. 


\section{DHA deficiency and human brain function}

Adequate delivery of maternal stored-DHA met the demand for DHA to the developing brain through breastfeeding and placental transfer. [16]. Thus, circulating maternal DHA is significantly related to the cognitive development of the descent. The improvement in attention scores, adaptability to new surroundings, mental development, memory performance, and hand-eye coordination are associated with higher maternal DHA delivery to the fetal brain $[7,190]$.

DHA deficiency is linked with different brain disorders such as major depressive and bipolar disorder [191,192]. DHA levels are positively correlated with improved learning and memory and reduced neuronal loss [183]. DHA deficiency affects epigenetic development in the feto-placental unit[193,194].

The DHA deficiency during pregnancy suggests lower development of language learning skills in children [195]. Even autistic spectrum disorder or ADHD among teenagers is associated with DHA deficiency [196,197]. Neurocognitive functional insufficiency in young adults or loneliness-related memory problems in middle age has been associated with DHA deficiency [198,199]. DHA deficiency in the third trimester significantly causes preterm brain development due to insufficient maternal consumption of n-3 fatty acids. Even following delivery, infants are entirely dependent on breast milk or formula milk for DHA and ARA. Reduced DHA consumption during this critical brain development period may influence brain functionalities in adult life [200]. 
Dementia has shown an inverse relationship with regular marine fish consumption in different continents $[112,201]$ and higher blood DHA levels inversely related to dementia[202,203]. Various brain diseases/disorders, such as Alzheimer's disease, Parkinson's disease, Huntington's disease, schizophrenia, mood disorders, are related to disturbed fatty acid signaling [204,205]. The most prevalent dementia is Alzheimer's disease, which is inversely related to brain DHA level. Serum DHA level reduces significantly, and its addition positively correlates with memory scores in elderly Alzheimer patients [111,206,207]. The plasma DHA level is significantly associated with the risk of Alzheimer's disease [208]. Intake of 200mg of DHA containing fishes per week reduces $60 \%$ risk of $\mathrm{AD}$ [209]. But different RCTs found mixed results with DHA supplementation. DHA alone or combined with ARA or the EPA found no significant neuropsychiatric status changes in Alzheimer's disease patients[115,116,210]. The neurodegenerative disorder, Parkinson's disease etiology is unknown. But its primary palliative treatment is dopamine-based therapy. Various animal studies found the neuroprotective effect of DHA in the Parkinson's disease model. DHA has been shown to improve L-DOPA-induced dyskinesia[211] and reduce dopaminergic neuron apoptosis in mouse models[113]. DHA supplements offer a beneficial neuroprotective effect for Parkinson's disease management [212].

Multiple factors influence serotonin biosynthesis and function. Brain serotonin level correlates with various behavioral consequences, e.g., control of executive function, sensory gating, social behavior, and impulsivity[213]. Serotonin-related gene 
polymorphism is associated with mental illnesses, e.g., autism spectrum disorders, ADHD, bipolar disorder, schizophrenia, etc. DHA modulates the activity of serotonin in the brain. DHA increases serotonin receptor accessibility by increasing membrane fluidity in postsynaptic neurons[213]. Concentric serotonin and a low DHA level in the orbitofrontal cortex are correlated with Schizophrenia[214].

Observational studies showed that ADHD also has a relationship with DHA levels. RCTs of DHA with EPA supplementation and addition of medications have demonstrated significant improvement in ADHD symptoms[114,215-226]. But DHA supplementation with methylphenidate didn't improve ADHD symptoms[227].

There are mixed results in RCTs that have been observed in early psychosis symptoms improvement with DHA supplementation. When DHA is supplemented with EPA for at least 12 weeks, the functional improvement and reduction of psychiatric symptoms are visible in different studies [228-230]. DHA deficiency elicits the chances of schizophrenia by promoter hypermethylation of nuclear receptor genes RxR and PPAR, which results in downregulation of the gamma-aminobutyric acid-ergic system and the prefrontal cortex involved in oligodendrocyte integrity[231]. Lower erythrocyte DHA status is associated with the development of bipolar disorder [232]. But combined DHA and EPA supplementation for 6 weeks improved mania and depression among juvenile patients [233-235]. However, recent RCT found DHA has no role in improving the symptoms of bipolar disorder [15]. 
7. Can DHA supplementation improve brain function of infants: results of clinical trials

Various randomized controlled trials (RCT) proved significant effects of DHA supplementation on infant brain development in pregnancy. The meta-analytic study in 2007 found a static co-relation between visual growth and DHA supplementation in $1^{\text {st }}$ year of life[117]. An RCT in 2011 showed DHA-supplemented 18 months old children had higher index scores in mental development [8]. Other RCT studies showed DHA-enriched fish oil supplemented children had significantly higher percentile ranks of the total number of gestures at 1 to 1.5 years of age[110]. DHAformula-fed infants scored equal visual equity scores with breast-fed infants at the age of four [236]. The recent meta-analytic review also found the positive effects of sea-food consumption in pregnancies in developing childhood neurocognitive function [46]. The supplementation of DHA to pregnant and nursing mothers and the first year of infant life have developed better cognitive ability. During the last trimester of pregnancy, fetal brain development demands a higher amount of DHA, which can be interrupted in the case of a preterm born baby and can result in mental growth retardation. Different RCTs showed that higher DHA enriched-formula (around 1\% of total fatty acids) is essential for the preterm baby for mental growth and development [16].

DHA supplemented along with EPA enhance the outcome for cognitive and mood disorders. But conflicting data exist about the effect of DHA supplementation 
on cognition during childhood. The earlier RCT conducted in Australia and Indonesia didn't show any improvement in general intelligence or attention among 6-10 years old children following 88mg/d DHA supplementation[237]. DHA Oxford Learning and Behaviour (DOLAB) study showed a significant improvement in brain function among aged 7-9 years[109]. Another RCT showed improved memory and learning ability among 7-9 years old children[238]. A few years ago, another RCT from Australia found no significant difference in academic performance between the DHA supplemented and control groups [239]. Although the authors have mentioned their study's limitation that the final assessment was finished by less than half of the study population, DHA supplementation was low. The study had conducted with slightly older children, and in some cases, mothers didn't give consent or provide data. Third National Health and Nutrition Examination Survey (NHANES III) found a higher DHA supplementation effect in girls than boys despite both sexes' received cognitive benefit [240]. The females need higher DHA supplementation for their own and for the growth and development of the newborn. Even the source of DHA and the ratio of EPA and DHA may influence the bioavailability of DHA.

A summary of few recent clinical trials has been shown in the following Table2. Although a slight improvement, these studies did not show any significant positive outcome from DHA supplementation effects on young children. However, a metaanalysis of DHA supplementation with the EPA improved childhood visual and psychomotor development without significant global IQ effects later in childhood 
[241]. However, there is no clinical data available where DHA supplementation was conducted before 14.5 weeks of gestational period.

Table 2: Various clinical studies of DHA supplementation in mothers and infants about brain function.

\begin{tabular}{|c|c|c|}
\hline Study name & Experimental setting & Observed outcome \\
\hline $\begin{array}{l}\text { The Kansas University } \\
\text { DHA outcome study } \\
\text { (KUDOS) clinical trial }\end{array}$ & $\begin{array}{l}\text { Cognitive and } \\
\text { behavioral } \\
\text { development }\end{array}$ & $\begin{array}{l}\text { Improvement of visual attention among } \\
\text { infants has been observed to reduce the } \\
\text { preterm birth risk [272]. }\end{array}$ \\
\hline $\begin{array}{l}\text { Effect of DHA } \\
\text { supplementation vs. } \\
\text { placebo } \\
\text { developmental } \\
\text { outcomes of toddlers } \\
\text { born preterm }\end{array}$ & $\begin{array}{l}\text { Developmental } \\
\text { outcomes of toddlers }\end{array}$ & $\begin{array}{l}\text { Daily supplementation of DHA didn't } \\
\text { improve cognitive function and may } \\
\text { adversely affect language development and } \\
\text { effortful control in specific subgroups of } \\
\text { children [273]. }\end{array}$ \\
\hline $\begin{array}{l}\text { Effect of DHA } \\
\text { supplementation } \\
\text { during pregnancy on } \\
\text { maternal depression } \\
\text { and } \\
\text { neurodevelopment of } \\
\text { young children }\end{array}$ & $\begin{array}{l}\text { Neurodevelopmental } \\
\text { outcome of children }\end{array}$ & $\begin{array}{l}\text { DHA supplementation during pregnancy did } \\
\text { not reduce postpartum depression in } \\
\text { mothers either improved cognitive and } \\
\text { language development in their offspring } \\
\text { during early childhood [274]. }\end{array}$ \\
\hline $\begin{array}{l}\text { Neurodevelopmental } \\
\text { outcomes of preterm } \\
\text { infants fed high-dose } \\
\text { docosahexaenoic acid }\end{array}$ & $\begin{array}{l}\text { Neurodevelopment at } \\
18 \text { months of age. }\end{array}$ & $\begin{array}{l}\text { It did not increase Bayley mental } \\
\text { development index scores of preterm infants } \\
\text { overall born earlier than } 33 \text { weeks but } \\
\text { improved the Bayley mental development } \\
\text { index scores of girls. }\end{array}$ \\
\hline $\begin{array}{l}\text { Neurodevelopmental } \\
\text { outcomes at } 7 \text { years } \\
\text { corrected age in } \\
\text { preterm infants who } \\
\text { were fed high-dose } \\
\text { docosahexaenoic acid } \\
\text { to term equivalent }\end{array}$ & $\begin{array}{l}\text { Cognitive outcome } \\
\text { detected at } 18 \text { months } \\
\text { age }\end{array}$ & Didn't show any evidence of benefit [275]. \\
\hline $\begin{array}{l}\text { Feeding preterm infant } \\
\text { milk with a higher } \\
\text { dose } \\
\text { docosahexaenoic acid }\end{array}$ & $\begin{array}{l}\text { Language or behavior } \\
\text { in early childhood. }\end{array}$ & $\begin{array}{l}\text { It did not result in any clinically meaningful } \\
\text { change to language development or behavior } \\
\text { when assessed in early childhood [276]. }\end{array}$ \\
\hline
\end{tabular}


than that used in current practice

\section{Roles of arachidonic acid in brain development and function}

Mother supplies both ARA and DHA to the growing and developing brain via placenta and breastfeeding. ARA uptake was found higher in early trimester trophoblast cells than EPA and DHA [242]. ARA may be required in a higher amount to support growth-promoting placental activities and production of eicosanoids. In human milk, the amount of ARA typically exceeds that the levels of DHA. Milk ARA content is also less varied than DHA, and, unlike DHA, ARA does not seem to be linked to maternal intake. There has been much discussion in recent years about the need for ARA and DHA in infant formula. Studies clearly show the requirement for both ARA and DHA in addition to the essential fatty acids (linoleic acid,18:2n-6 (LA), and alpha-linolenic acid, 18:3n-3 (ALA) to support the optimal body, brain growth, and brain function. ARA is quantitatively the most common LCPUFAs in the brain after the DHA[243]. Although DHA's neuroprotective properties are documented, the roles of ARA in brain development and functions have not been investigated to a greater extent. Given that ARA and its precursor, LA, contribute significantly to the Western diet and its pleiotropic biological effects and its interactions with DHA, this n-6 LCPUFA is a crucial modifiable factor in brain development and preventive 
strategies of brain diseases. ARA corresponds to around $20 \%$ of the total amount of neuronal fatty acids and is mainly esterified in membrane phospholipids.

Several studies have suggested that the structure-function and metabolism of the brain depend on levels of ARA and DHA and interactions of their metabolites[29]. ARA must either be consumed in the diet or synthesized from its precursor LA in the liver. The brain contains relatively low LA levels, and its conversion into ARA is minimum in the brain. Thus the brain depends on a steady supply of ARA[244] from the circulation. Although lipoproteins and lysophospholipids of plasma may contribute to brain ARA levels, their quantitative contribution is unknown. Plasma unesterified ARA enters the brain at $17.8 \mathrm{mg} /$ day per the whole brain in adult humans. Upon its entry into the brain, ARA is activated by a long-chain acyl-CoA synthetase and can be esterified into the sn-2 position of phospholipids. During neurotransmission, the brain ARA cascade is initiated when ARA is released from synaptic membrane phospholipid by neuroreceptor-initiated activation of cPLA2. PLA 2 is activated by dopaminergic, cholinergic, glutamatergic, and serotonergic stimulation via G-proteins or calcium[245]. Several PLA2 are activated via serotonergic (5-hydroxytryptaminergic), glutamatergic, dopaminergic, and cholinergic receptors [245,246]. Usually, calciumdependent cytosolic PLA2 $\left(\mathrm{cPLA}_{2}\right)$ resides at the postsynaptic terminals, selective for releasing ARA, whereas calcium-independent PLA2 is believed to release the DHA sn2 position of phospholipids $[13,14]$. Upon its release, a portion of the unesterified ARA is converted to prostaglandins, leukotrienes, and lipoxins, a portion oxidized via $\beta$ oxidation, and the remainder (approx. 97\% under basal conditions) is activated by 
ACSL and ultimately recycled and re-esterified into the sn-2 position of phospholipids[247]. An additional ARA is released by activated cytokine and glutamatergic N-methyl-d-aspartate receptors in conditions such as neuroinflammation and excitotoxicity. Although the signals that ARA and its derivatives relay are not entirely understood, they regulate blood flow, neuroinflammation, excitotoxicity, the sleep/wake cycle, and neurogenesis[248].

ARA itself is also directly involved in synaptic functions. The level of intracellular free ARA and the balance between the releasing and incorporating enzymes in membrane phospholipids may play critical roles in neuroinflammation and synaptic dysfunction. Both these events are observed in the murine model of Alzheimer's disease before the amyloid plaques and the neurofibrillary tangles, respectively formed by the two agents known for Alzheimer's disease agents, $A \beta$ peptide and hyperphosphorylated tau. Finally, western food, which contains excessive n-6 / n-3 ratios, might favor more ARA levels and influence Alzheimer's disease mechanisms.

A better understanding of the complex relationships between ARA and DHA and their brain mechanisms is required. Free ARA contributes to Alzheimer's disease progression via different pathways. Figure-3 describes different metabolites of ARA involved in brain function. ARA and derivatives are pro-inflammatory and participate in neuroinflammation. ARA is directly involved in synaptic functions as a retrograde messenger and a regulator of neuro mediator exocytosis. ARA also influences tau phosphorylation, and polymerization can compete with DHA. Moreover, ARA has 
pleiotropic effects on brain disease, and it may be used in the fight against brain diseases. The dietary ARA and brain diseases about DHA should be investigated further to prevent the disease.

\section{Figure-3: Metabolites of ARA and their receptors}

ARA is converted to lipoxinA4 or lipoxinB4 via two different pathways. Lipoxins mediate their action on endothelial cells to offer an inflammation resolution process. LipoxinA4 lowers neuroinflammation by reducing microglial activation. LTA4, LTB4, LTC4, LTD4, and LTE4 are leukotrienes $A 4, B 4, C 4, D 4$, and E4, respectively; DP1, EP1-EP4, FP, and IP, prostaglandin receptors; $T P$, thromboxane $A 2$ receptor; $B L T 1$ and $B L T 2$, leukotriene $B 4$ receptor; CysLT1 and CysLT2: cysteinyl leukotriene receptors; ALXR: lipoxins receptor.

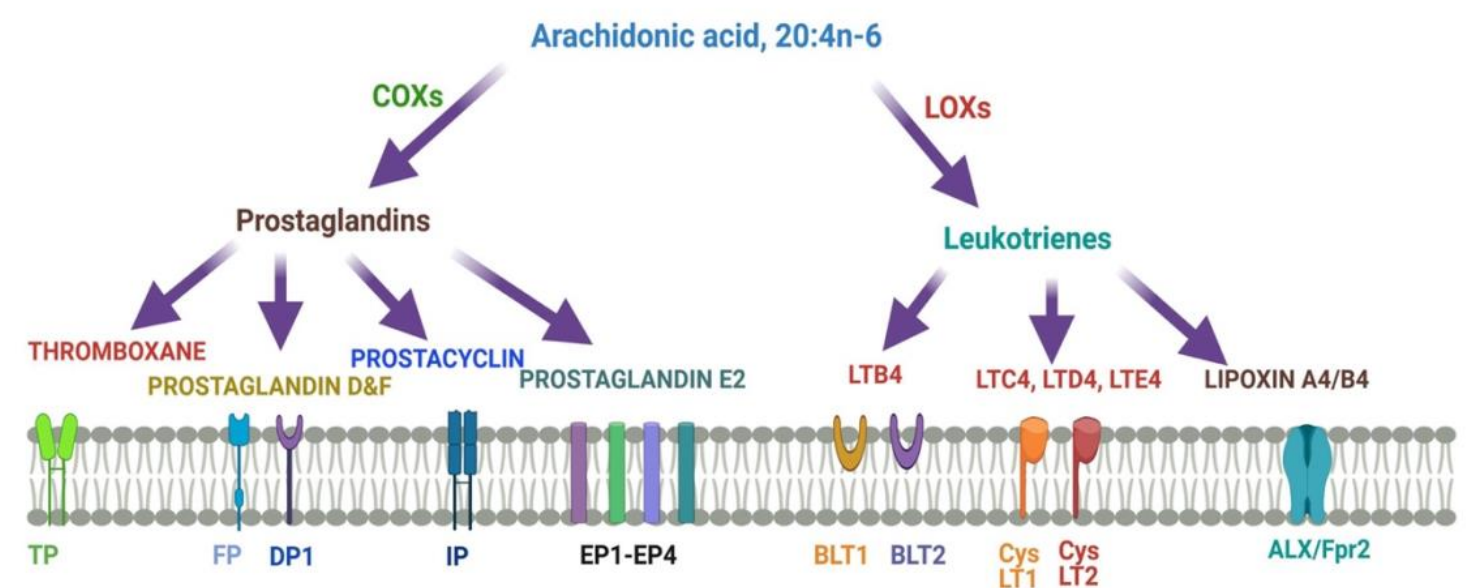

The transgenic Alzheimer's disease murine model showed that dietary ARA produced opposite $A \beta$ production in Alzheimer's disease. Studies are required on the impact of dietary ARA on Alzheimer's disease and identify the underlying mechanisms of 
action. A reduced level of ARA in the temporal cortex of Alzheimer's patients was observed [249], however, its relation with DHA and its metabolites is unknown.

$\mathrm{CPLA}_{2}-\alpha$ activation by $\mathrm{A} \beta$ oligomers is an early step in the induction of neuronal apoptosis[250]. Suppression of $\mathrm{cPLA}_{2}-\alpha$ expression in mice produces resistance to A $\beta$ peptide in the transgenic J20 mouse line [251,252]. ARA involvement in Alzheimer's disease was mediated via $\mathrm{CPLA}_{2} \alpha$ as the ARA-enriched diet prevented cognitive dysfunction in Tg2576 mice by altering APP processing and reduced synthesis of amyloid plaques and APP processing in ARA-fed brains Tg2576 mice at the age of 17 months. However, a DHA-rich diet did not show such effects [253]. A diet containing 2\% ARA for 21 weeks increased $A \beta_{1-42}$ production and deposition in 24 weeks old CRND8 mice.

Neuroinflammation has both beneficial and harmful effects in Alzheimer's disease as it produces $\mathrm{A} \beta$ and degrades synapses. The most abundant prostaglandins

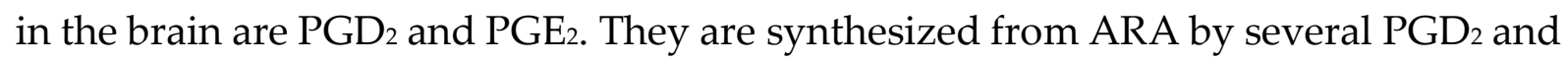
PGE2 synthases. COX-2 is overexpressed in the cortex and hippocampus of Alzheimer's disease patients [254]. Levels of hematopoietic $\mathrm{PGD}_{2}$ synthase (one of the two $\mathrm{PGD}_{2}$ synthases expressed in the brain) are increased in microglial cells and astrocytes of Alzheimer's disease transgenic mice, and Alzheimer's disease patients[255]. PGE2 increases neuroinflammation and amplifies Alzheimer's disease pathology through various mechanisms. 
ARA-derived lipoxins are anti-inflammatory eicosanoids distinct from proinflammatory leukotriene and prostaglandin. Lipoxin biosynthesis occurs via two different pathways. Lipoxins mediate their action on endothelial cells to offer an inflammation resolution process. LipoxinA4 lowers neuroinflammation by reducing microglial activation. 5- Lipoxygenase (5-LOX) converts ARA into 5-HPETE and then 5-HETE or leukotriene A4 (LTA4). Increased expression of the dual enzyme 12/15LOX and its products, 12(S)-HETE and 15(S)-HETE, was reported in fronthe tal and temporal brain regions cerebrospinal fluid, respectively, in Alzheimer's disease patients.

Finally, endocannabinoids containing ARA are involved in Alzheimer's disease via the $\mathrm{CB} 2$ receptor. Expression levels of the $\mathrm{CB} 2$ receptor are correlated with $\mathrm{A} \beta$ deposits but not associated with the patients' cognitive status. Although neuroinflammation is related to Alzheimer's disease, there is no evidence that higher brain contents of ARA would produce inflammation.

Several animal studies indicate that ARA has beneficial effects on cognition and synaptic plasticity[256]. An association between abilities of spatial memory and ARA content of the hippocampus was reported. ARA modulates $\mathrm{Kv}$ channels at the postsynaptic membrane, thus influences long-term potentiation [257]. ARA induces presynaptic long-term depression associated with a $\mathrm{Ca}^{2+}$ influx and activation of metabotropic glutamate receptors[257].

In addition to its effects on long-term potentiation or long-term depression at the postsynaptic level, ARA can induce neurotransmitter exocytosis in the presynaptic 
neuron via activation of the soluble $\mathrm{N}$-ethylmaleimide-attachment receptors (SNARE). ARA induces the binding of syntaxin-1 to the SNARE complex in the presence of Munc18-1, which is a critical regulator of the process[258]. Although ARA's role in synaptic function is well documented, the benefit or drawback may depend on the delicate balance in ARA levels. Age and A $\beta$ concentration or other physiological factors could modify ARA's effects on synapse and neuronal cells. Additional work is now required to characterize dietary ARA's influence on associated brain diseases.

The mechanisms of ARA transportation to the brain and inside the brain are still poorly understood, and more efforts are needed for their nuanced characterization. The biological roles of several ACSLs and LPATs for incorporating ARA in the membrane phospholipids have been studied[247]. Some of them are relatively specific for ARA, such as ACLS4, LPIAT1, and LPCAT3. However, polymorphisms and variations in their expression levels can modify the incorporation rate of ARA in the different tissues, including the brain, for the same food intake. Nutritional recommendations regarding the ARA intake must be based on the knowledge of such variations.

ARA's effects on brain signaling functions described above are based on the fact that free ARA is released from membrane phospholipid by cPLA $2 \alpha$ or secretory PLA2. It is not known whether higher ARA amounts in specific phospholipid classes in the brain favor ARA release by these PLA2 and lead to higher free ARA levels in neuronal or glial cells. Therefore lipidomic and cell biology studies must be performed to 
determine the effect of ARA brain uptake on its release and conversion into pro- or anti-inflammatory derivatives.

While the competition between n- 6 and n-3 fatty acids and their precursors for the desaturases, COXs, and LOXs are known, but little is known on the competition between ARA and DHA in incorporation in the brain. Mfsd2A transports DHA to the brain in the form DHA-LPC [57], but brain ARA content was increased by $30 \%$ in Mfsd2A knockout mice, whereas that of DHA was reduced by $58 \%$. These fatty acid changes were accompanied by neuronal loss in the hippocampus and cerebellum with severe cognitive deficits and anxiety. Therefore, the deposition of ARA to the brain is not altered by reduced expression of Mfsd2A. However, under this circumstance, ARA replaced DHA in phospholipids but could not play the roles of DHA in neuronal functions[57].

FABPs also have different affinities for ARA and DHA. FABP5 and FABP7 are more selective for DHA, whereas FABP3 binds ARA with much higher affinity $[259,260]$. Regarding fatty acid metabolizing enzymes, DHA is preferentially used as a substrate by ACSL6[261] and calcium-independent group VI PLA2 [262] , whereas ACSL4 and group IV cPLA2 used ARA as preferred substrate.

Both ARA and DHA are sources of phospholipids in the synaptic cell membrane fluidity that controls the functions of receptors, transporters, and membrane-bound proteins. ARA and DHA are required to replenish brain injury, vascular regulation, and brain development in preterm babies. ARA is needed to support endothelial cells during brain injury, while DHA is required to support membrane fluidity for the receptors and linear growth and network of 
neuronal cells. Neuroprotective actions of DHA in pre-term are manifested with antiinflammatory initiation and resolutions by its own and its signaling lipid mediators in particular. AA and DHA produced different sets of pro-resolving lipid bioactive. Lipoxins are derived from ARA, while resolvin (neuro) protectin and maresins are derived from EPA and DHA. LXA4 receptor staining in the brain indicates that lipoxinA4 lowers neuroinflammation and brain edema during brain injury [263]. The anti-inflammatory lipoxin A4 acts as an endogenous allosteric modulator of cannabinoid receptor [264]. Thus, in contrast to PGE2, which shows proinflammatory actions, lipoxins offer an inflammation resolution process.

\section{Conclusions}

As an integral part of brain structure and function, DHA is required throughout life. DHA is an important building block of the brain structure and involved several levels of brain function by using various metabolites in transcriptional and signaling systems in neurodevelopment pathways Figure-4 details DHA metabolites and their global effects on gene expression and second messenger systems affecting multiple cellular functions.

The data on maternal and infant nutritional intakes are not yet consistent despite the fact that DHA's impact on brain development and function is being investigated extensively for the last two decades. Due to some conflicting reports on the association with LCPUFAs supplementation and cognitive development, it has become more critical to determine optimum DHA doses for effective neurodevelopment at different ages [265-267]. Further studies on emerging DHA 
metabolites are also required to assess different clinical outcomes, including mental health status and life quality.

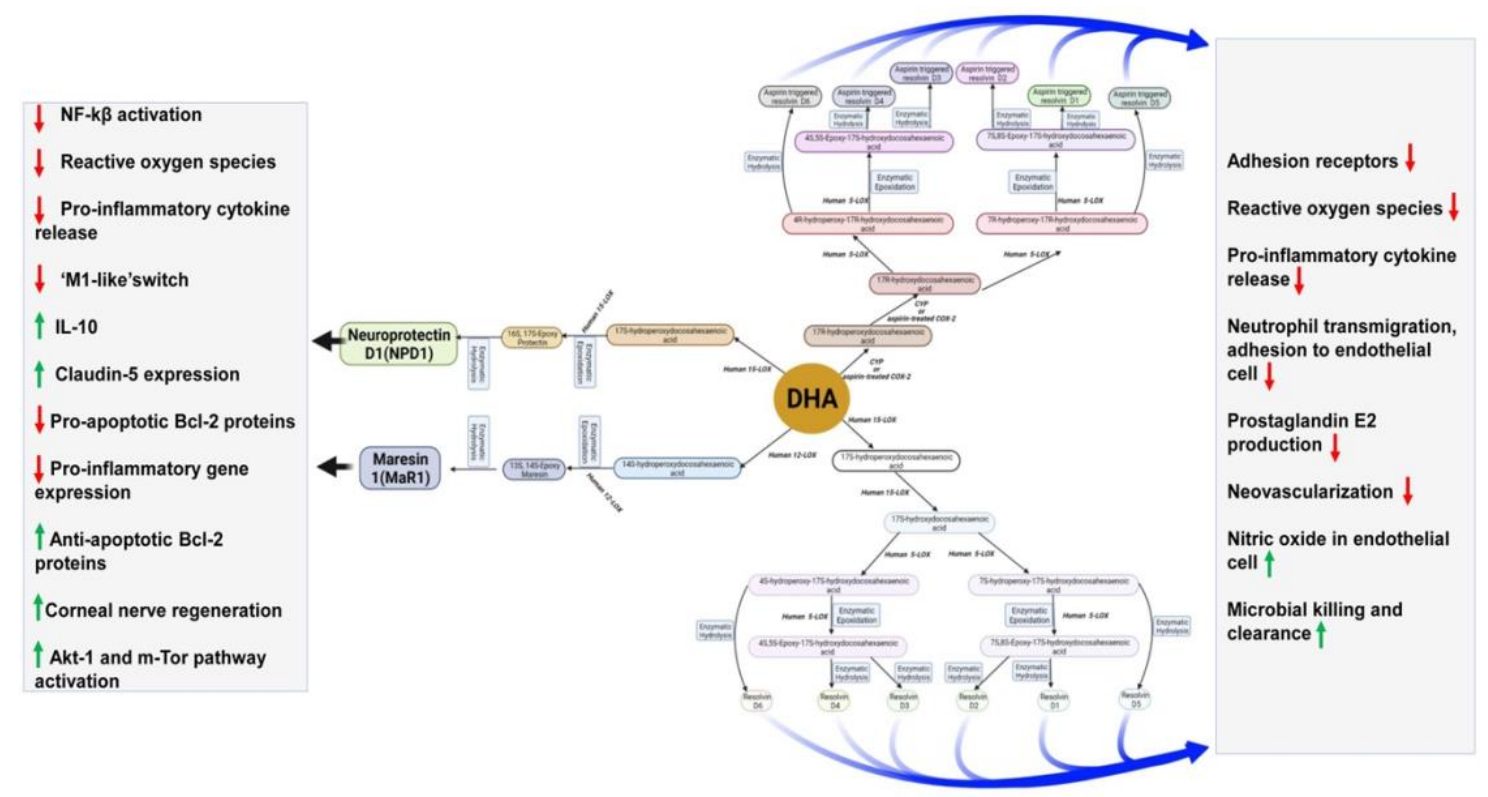

Figure -4 DHA metabolites formation and function in the brain

DHA is converted to specialized pro-resolving mediators (SPM) such as maresin 1(MaR1), neuroprotectin D1(NPD1), and resolvins by human 12-LOX, 15-LOX, and CYP or aspirintreated COX-2 enzymatically. These metabolites have multiple functions in the brain, which have been mentioned in the boxes. DHA is metabolized by the P450 system, cyclooxygenase, and lipoxygenase enzymes under different metabolic conditions.

Interestingly most of the RCTs, especially in behavioral disorders, mainly focused on either EPA and DHA combination therapy or only EPA supplementation, which indicates more studies based on DHA supplementation are required. Epidemiological studies report a strong association between low dietary intake of DHA and a higher risk of brain diseases. Turnover of ARA and DHA in brain 
membrane phospholipids is rapid and energy-consuming. The recycling (deesterification-re-esterification) of these two fatty acids in the brain are independently are carried out by ARA- and DHA-selective enzymes. The ARARA-mediated processes can be targeted or altered separately from the DHA -mediated processes by a dietary deficiency of n-3 PUFA or genetic manipulation. Therefore, in n-3 PUFA deficiency, the homeostatic mechanisms show brain DHA loss in the brain while increasing ARA metabolism.

Turnover of ARA in brain membrane phospholipids is involved the bipolar disorder. The downregulation of the turnover correlates with reduced expression of ARA-selective cPLA2 or acyl-CoA synthetase and COX-2[247]. Further studies are required to understand the impact of the $n-6 / n-3$ ratio on the regulation of DHAselective iPLA2 and COX-1 or ARA-selective cPLA2, sPLA2, and COX-2 and their effects on brain function and neuroinflammation.

The mean concentrations of DHA and ARA in breast milk can vary based on the maternal diet [263]. The group with the highest levels of DHA showed decreased ARA levels in two brain areas, suggesting competition of DHA with ARA. The optimal balance of DHA and ARA intake during infancy is still unknown, but current best practice offers that the amount of DHA in infant formula should not exceed the amount of ARA[268]. The effect of DHA and ARA status and supplementation in infancy has been evaluated mainly through global developmental assessments focused on the attainment of normative milestones. However, more granular measures of specific cognitive function may be more sensitive markers of these effects. This 
suggests that high doses of DHA may suppress the benefits of ARA. Studies showed that absolute levels of n-3 PUFAs and the ratio of n-6 and n-3 PUFA affect gene expression of controlling neurogenesis and neural function. Still, the absolute levels of ARA and DHA could be more important than their ratio, in particular with the pre-term infant. ARA supports the first year of developmental growth as conditional deficiency of ARA is established in preterm infants [269]. The pre-term infant received formula with the $n-6 / n-3$ ratio of 2:1 showed a higher level of LCPUFAs and improved psychomotor development than the n-6/n-3 ratio of $1: 1$ group suggest ARA and DHA ratio of 2: 1 in the formula for the very preterm infant [270]. Thus, the common requirement for nutritional supports needs both ARA and DHA for vascular and neuronal development, in particular with pregnancies where supply these nutrients halted prematurely [271]. The supplementation of DHA: ARA in infant formulas, ranges from 1:1 to 1:2. The present recommendations with DHA and ARA levels are $0.2 \%$ to $0.4 \%$ and $0.35 \%$ to $0.7 \%$ of total fatty acids are appropriate[272]. The formula should reflect human milk composition for optimal neurocognitive benefits.

\section{Author Contributions}

Conceptualization, A.K.D.; Methodology, A.K.D., and S.B.; Investigation, A.K.D. Original Draft Preparation A.K.D.; Writing-Review \& Editing, A.K.D., S.B. RM; AB, SP; Visualization, R.M., S.B., and A.K.D.; Supervision, A.K.D. All authors have read and agreed to the published version of the manuscript.

\section{Funding}

This research received no external funding.

\section{Acknowledgments}


This work is supported in part by the grants from Throne Holst Foundation and the

Faculty of Medicine, University Oslo, Norway.

\section{Conflicts of Interest}

The authors express no conflict of interest.

\section{References:}

1. Nyaradi, A.; Li, J.; Hickling, S.; Foster, J.; Oddy, W.H. The role of nutrition in children's neurocognitive development, from pregnancy through childhood. Front Hum Neurosci 2013, 7, 97, doi:10.3389/fnhum.2013.00097.

2. Martinez, M.; Conde, C.; Ballabriga, A. Some chemical aspects of human brain development. II. Phosphoglyceride fatty acids. Pediatr Res 1974, 8, 93-102, doi:10.1203/00006450-197402000-00005.

3. Clandinin, M.T.; Chappell, J.E.; Leong, S.; Heim, T.; Swyer, P.R.; Chance, G.W. Intrauterine fatty acid accretion rates in human brain: implications for fatty acid requirements. Early Hum Dev 1980, 4, 121-129, doi:10.1016/0378-3782(80)90015-8.

4. Lauritzen, L.; Brambilla, P.; Mazzocchi, A.; Harslof, L.B.; Ciappolino, V.; Agostoni, C. DHA Effects in Brain Development and Function. Nutrients 2016, 8, doi:10.3390/nu8010006.

5. Agostoni, C.; Trojan, S.; Bellu, R.; Riva, E.; Giovannini, M. Neurodevelopmental quotient of healthy term infants at 4 months and feeding practice: the role of long-chain polyunsaturated fatty acids. Pediatr Res 1995, 38, 262-266, doi:10.1203/00006450$199508000-00021$.

6. Agostoni, C.; Trojan, S.; Bellu, R.; Riva, E.; Bruzzese, M.G.; Giovannini, M. Developmental quotient at 24 months and fatty acid composition of diet in early infancy: a follow up study. Arch Dis Child 1997, 76, 421-424, doi:10.1136/adc.76.5.421. 
7. Helland, I.B.; Smith, L.; Saarem, K.; Saugstad, O.D.; Drevon, C.A. Maternal supplementation with very-long-chain n-3 fatty acids during pregnancy and lactation augments children's IQ at 4 years of age. Pediatrics 2003, 111, e39-44, doi:10.1542/peds.111.1.e39.

8. Drover, J.R.; Hoffman, D.R.; Castañeda, Y.S.; Morale, S.E.; Garfield, S.; Wheaton, D.H.; Birch, E.E. Cognitive function in 18-month-old term infants of the DIAMOND study: a randomized, controlled clinical trial with multiple dietary levels of docosahexaenoic acid. Early Hum Dev 2011, 87, 223-230, doi:10.1016/j.earlhumdev.2010.12.047.

9. Innis, S.M. Perinatal biochemistry and physiology of long-chain polyunsaturated fatty acids. J Pediatr 2003, 143, S1-8, doi:10.1067/s0022-3476(03)00396-2.

10. Jensen, C.L.; Voigt, R.G.; Prager, T.C.; Zou, Y.L.; Fraley, J.K.; Rozelle, J.C.; Turcich, M.R.; Llorente, A.M.; Anderson, R.E.; Heird, W.C. Effects of maternal docosahexaenoic acid intake on visual function and neurodevelopment in breastfed term infants. Am J Clin Nutr2005, 82, 125-132, doi:10.1093/ajcn.82.1.125.

11. Dutta-Roy, A.K. Transport mechanisms for long-chain polyunsaturated fatty acids in the human placenta. In American Journal of Clinical Nutrition, 2000.

12. Basak, S.; Mallick, R.; Duttaroy, A.K. Maternal Docosahexaenoic Acid Status during Pregnancy and Its Impact on Infant Neurodevelopment. Nutrients 2020, 12, doi:10.3390/nu12123615.

13. Lauritzen, L.; Carlson, S.E. Maternal fatty acid status during pregnancy and lactation and relation to newborn and infant status. Matern Child Nutr 2011, 7 Supp/ 2, 41-58, doi:10.1111/j.1740-8709.2011.00303.x.

14. Browning, L.M.; Walker, C.G.; Mander, A.P.; West, A.L.; Madden, J.; Gambell, J.M.; Young, S.; Wang, L.; Jebb, S.A.; Calder, P.C. Incorporation of eicosapentaenoic and 
docosahexaenoic acids into lipid pools when given as supplements providing doses equivalent to typical intakes of oily fish. Am J Clin Nutr 2012, 96, 748-758, doi:10.3945/ajcn.112.041343.

15. Ciappolino, V.; DelVecchio, G.; Prunas, C.; Andreella, A.; Finos, L.; Caletti, E.; Siri, F.; Mazzocchi, A.; Botturi, A.; Turolo, S., et al. The Effect of DHA Supplementation on Cognition in Patients with Bipolar Disorder: An Exploratory Randomized Control Trial. Nutrients 2020, 12, doi:10.3390/nu12030708.

16. Weiser, M.J.; Butt, C.M.; Mohajeri, M.H. Docosahexaenoic Acid and Cognition throughout the Lifespan. Nutrients 2016, 8, 99, doi:10.3390/nu8020099.

17. Hahn-Holbrook, J.; Fish, A.; Glynn, L.M. Human Milk Omega-3 Fatty Acid Composition is Associated with Infant Temperament. Nutrients 2019, 11, doi:10.3390/nu11122964.

18. Grey, K.R.; Davis, E.P.; Sandman, C.A.; Glynn, L.M. Human milk cortisol is associated with infant temperament. Psychoneuroendocrinology 2013, 38, 1178-1185, doi:10.1016/j.psyneuen.2012.11.002.

19. Lin, P.Y.; Su, K.P. A meta-analytic review of double-blind, placebo-controlled trials of antidepressant efficacy of omega-3 fatty acids. Journal of Clinical Psychiatry 2007, 68, 1056-1061, doi:10.4088/JCP.v68n0712.

20. Clayton, E.H.; Hanstock, T.L.; Hirneth, S.J.; Kable, C.J.; Garg, M.L.; Hazell, P.L. Long-chain omega-3 polyunsaturated fatty acids in the blood of children and adolescents with juvenile bipolar disorder. Lipids 2008, 43, 1031-1038, doi:10.1007/s11745-008-3224-z.

21. Bhatia, H.S.; Agrawal, R.; Sharma, S.; Huo, Y.X.; Ying, Z.; Gomez-Pinilla, F. Omega-3 fatty acid deficiency during brain maturation reduces neuronal and behavioral plasticity in adulthood. PLoS One 2011, 6, e28451, doi:10.1371/journal.pone.0028451. 
22. Su, K.P. Biological mechanism of antidepressant effect of omega-3 fatty acids: how does fish oil act as a 'mind-body interface'? Neurosignals 2009, 17, 144-152, doi:10.1159/000198167.

23. Innis, S.M.; Friesen, R.W. Essential n-3 fatty acids in pregnant women and early visual acuity maturation in term infants. Am J Clin Nutr 2008, 87, 548-557, doi:87/3/548 [pii].

24. Yavin, E.; Himovichi, E.; Eilam, R. Delayed cell migration in the developing rat brain following maternal omega 3 alpha linolenic acid dietary deficiency. Neuroscience 2009, 162, 1011-1022, doi:10.1016/j.neuroscience.2009.05.012.

25. Su, K.P.; Matsuoka, Y.; Pae, C.U. Omega-3 Polyunsaturated Fatty Acids in Prevention of Mood and Anxiety Disorders. Clin Psychopharmacol Neurosci 2015, 13, 129-137, doi:10.9758/cpn.2015.13.2.129.

26. Brunst, K.J.; Enlow, M.B.; Kannan, S.; Carroll, K.N.; Coull, B.A.; Wright, R.J. Effects of Prenatal Social Stress and Maternal Dietary Fatty Acid Ratio on Infant Temperament: Does Race Matter? Epidemiology (Sunnyvale) 2014, 4, doi:10.4172/2161-1165.1000167.

27. Mallick, R.; Basak, S.; Duttaroy, A.K. Docosahexaenoic acid,22:6n-3: Its roles in the structure and function of the brain. International journal of developmental neuroscience : the official journal of the International Society for Developmental Neuroscience 2019, 79, 21-31, doi:10.1016/j.ijdevneu.2019.10.004.

28. Duvall, M.G.; Levy, B.D. DHA- and EPA-derived resolvins, protectins, and maresins in airway inflammation. European Journal of Pharmacology 2016, 785, 144-155, doi:10.1016/j.ejphar.2015.11.001.

29. Contreras, M.A.; Rapoport, S.I. Recent studies on interactions between $n-3$ and n-6 polyunsaturated fatty acids in brain and other tissues. Curr Opin Lipido/2002, 13, 267272, doi:10.1097/00041433-200206000-00006. 
30. Authority, E.F.S. Scientific Opinion on the substantiation of health claims related to docosahexaenoic acid (DHA), eicosapentaenoic acid (EPA). EFSA Journal 2011, 10.2903/j.efsa.2011.2078, doi:10.2903/j.efsa.2011.2078.

31. Lauritzen, L.; Brambilla, P.; Mazzocchi, A.; Harsløf, L.B.S.; Ciappolino, V.; Agostoni, C. DHA effects in brain development and function. In Nutrients, 2016.

32. Carver, J.D.; Benford, V.J.; Han, B.; Cantor, A.B. The relationship between age and the fatty acid composition of cerebral cortex and erythrocytes in human subjects. Brain Research Bulletin 2001, 10.1016/S0361-9230(01)00551-2, doi:10.1016/S03619230(01)00551-2.

33. Innis, S.M. Dietary omega 3 fatty acids and the developing brain. Brain Res 2008, 1237, 35-43, doi:10.1016/j.brainres.2008.08.078.

34. Cetin, I.; Alvino, G.; Cardellicchio, M. Long chain fatty acids and dietary fats in fetal nutrition. In Journal of Physiology, 2009; 10.1113/jphysiol.2009.173062.

35. Duttaroy, A.K. Transport of fatty acids across the human placenta: A review. In Progress in Lipid Research, 2009; pp 52-61.

36. Sherry, C.L.; Oliver, J.S.; Marriage, B.J. Docosahexaenoic acid supplementation in lactating women increases breast milk and plasma docosahexaenoic acid concentrations and alters infant omega 6:3 fatty acid ratio. Prostaglandins Leukot Essent Fatty Acids 2015, 95, 63-69, doi:10.1016/j.plefa.2015.01.005.

37. Calder, P.C. The DHA content of a cell membrane can have a significant influence on cellular behaviour and responsiveness to signals. Annals of Nutrition and Metabolism 2016, 10.1159/000448262, doi:10.1159/000448262. 
38. Basak, S.; Das, M.K.; Duttaroy, A.K. Fatty acid-induced angiogenesis in first trimester placental trophoblast cells: Possible roles of cellular fatty acid-binding proteins. Life Sciences 2013, 93, 755-762, doi:10.1016/j.lfs.2013.09.024.

39. Johnsen, G.M.; Basak, S.; Weedon-Fekjaer, M.S.; Staff, A.C.; Duttaroy, A.K. Docosahexaenoic acid stimulates tube formation in first trimester trophoblast cells, HTR8/SVneo. Placenta 2011, 32, 626-632, doi:10.1016/j.placenta.2011.06.009.

40. Khong, Y.; Brosens, I. Defective deep placentation. In Best Practice and Research: Clinical Obstetrics and Gynaecology, 2011.

41. Campbell, F.M.; Dutta-Roy, A.K. Plasma membrane fatty acid-binding protein (FABPpm) is exclusively located in the maternal facing membranes of the human placenta. FEBS Lett 1995, 375, 227-230, doi:0014-5793(95)01216-2 [pii].

42. Bourre, J.M. Dietary omega-3 fatty acids for women. Biomed Pharmacother 2007, 61, 105-112, doi:10.1016/j.biopha.2006.09.015.

43. Jorgensen, M.H.; Nielsen, P.K.; Michaelsen, K.F.; Lund, P.; Lauritzen, L. The composition of polyunsaturated fatty acids in erythrocytes of lactating mothers and their infants. Matern Child Nutr 2006, 2, 29-39, doi:10.1111/j.1740-8709.2006.00039.x.

44. Koletzko, B.; Schmidt, E.; Bremer, H.J.; Haug, M.; Harzer, G. Effects of dietary long-chain polyunsaturated fatty acids on the essential fatty acid status of premature infants. Eur J Pediatr 1989, 148, 669-675, doi:10.1007/BF00441531.

45. Innis, S.M. Chapter 10 Essential fatty acid metabolism during early development. Biology of Growing Animals 2005, 10.1016/S1877-1823(09)70017-7, doi:10.1016/S1877-1823(09)70017-7.

46. Hibbeln, J.R.; Spiller, P.; Brenna, J.T.; Golding, J.; Holub, B.J.; Harris, W.S.; Kris-Etherton, P.; Lands, B.; Connor, S.L.; Myers, G., et al. Relationships between seafood consumption 
during pregnancy and childhood and neurocognitive development: Two systematic reviews. Prostaglandins Leukot Essent Fatty Acids 2019, 151, 14-36, doi:10.1016/j.plefa.2019.10.002.

47. Oddy, W.H.; Kendall, G.E.; Li, J.; Jacoby, P.; Robinson, M.; de Klerk, N.H.; Silburn, S.R.; Zubrick, S.R.; Landau, L.I.; Stanley, F.J. The long-term effects of breastfeeding on child and adolescent mental health: a pregnancy cohort study followed for 14 years. J Pediatr 2010, 156, 568-574, doi:10.1016/j.jpeds.2009.10.020.

48. Van Elswyk, M.E.; Kuratko, C. Achieving adequate DHA in maternal and infant diets. J Am Diet Assoc 2009, 109, 403-404; author reply 404, doi:10.1016/j.jada.2009.01.004.

49. Cohen, J.T.; Bellinger, D.C.; Connor, W.E.; Shaywitz, B.A. A quantitative analysis of prenatal intake of n-3 polyunsaturated fatty acids and cognitive development. Am J Prev Med 2005, 29, 366-374, doi:10.1016/j.amepre.2005.06.008.

50. Dunstan, J.A.; Simmer, K.; Dixon, G.; Prescott, S.L. Cognitive assessment of children at age 2(1/2) years after maternal fish oil supplementation in pregnancy: a randomised controlled trial. Arch Dis Child Fetal Neonatal Ed 2008, 93, F45-50, doi:10.1136/adc.2006.099085.

51. Oddy, W.H.; Li, J.; Whitehouse, A.J.; Zubrick, S.R.; Malacova, E. Breastfeeding duration and academic achievement at 10 years. Pediatrics 2011, 127, e137-145, doi:10.1542/peds.2009-3489.

52. Kramer, M.S.; Aboud, F.; Mironova, E.; Vanilovich, I.; Platt, R.W.; Matush, L.; Igumnov, S.; Fombonne, E.; Bogdanovich, N.; Ducruet, T., et al. Breastfeeding and child cognitive development: new evidence from a large randomized trial. Arch Gen Psychiatry 2008, 65, 578-584, doi:10.1001/archpsyc.65.5.578. 
53. Caspi, A.; Williams, B.; Kim-Cohen, J.; Craig, I.W.; Milne, B.J.; Poulton, R.; Schalkwyk, L.C.; Taylor, A.; Werts, H.; Moffitt, T.E. Moderation of breastfeeding effects on the IQ by genetic variation in fatty acid metabolism. Proc Natl Acad Sci U S A 2007, 104, 1886018865, doi:10.1073/pnas.0704292104.

54. Kadry, H.; Noorani, B.; Cucullo, L. A blood-brain barrier overview on structure, function, impairment, and biomarkers of integrity. Fluids Barriers CNS 2020, 17, 69, doi:10.1186/s12987-020-00230-3.

55. Bernoud, N.; Fenart, L.; Moliere, P.; Dehouck, M.P.; Lagarde, M.; Cecchelli, R.; Lecerf, J. Preferential transfer of 2-docosahexaenoyl-1-lysophosphatidylcholine through an in vitro blood-brain barrier over unesterified docosahexaenoic acid. J Neurochem 1999, 72, 338-345, doi:10.1046/j.1471-4159.1999.0720338.x.

56. Tiwary, S.; Morales, J.E.; Kwiatkowski, S.C.; Lang, F.F.; Rao, G.; McCarty, J.H. Metastatic Brain Tumors Disrupt the Blood-Brain Barrier and Alter Lipid Metabolism by Inhibiting Expression of the Endothelial Cell Fatty Acid Transporter Mfsd2a. Sci Rep 2018, 8, 8267, doi:10.1038/s41598-018-26636-6.

57. Nguyen, L.N.; Ma, D.; Shui, G.; Wong, P.; Cazenave-Gassiot, A.; Zhang, X.; Wenk, M.R.; Goh, E.L.; Silver, D.L. Mfsd2a is a transporter for the essential omega-3 fatty acid docosahexaenoic acid. Nature 2014, 509, 503-506, doi:10.1038/nature13241.

58. Chan, J.P.; Wong, B.H.; Chin, C.F.; Galam, D.L.A.; Foo, J.C.; Wong, L.C.; Ghosh, S.; Wenk, M.R.; Cazenave-Gassiot, A.; Silver, D.L. The lysolipid transporter Mfsd2a regulates lipogenesis in the developing brain. PLoS Biol 2018, 16, e2006443, doi:10.1371/journal.pbio.2006443.

59. Guemez-Gamboa, A.; Nguyen, L.N.; Yang, H.; Zaki, M.S.; Kara, M.; Ben-Omran, T.; Akizu, N.; Rosti, R.O.; Rosti, B.; Scott, E., et al. Inactivating mutations in MFSD2A, required for 
omega-3 fatty acid transport in brain, cause a lethal microcephaly syndrome. Nat Genet 2015, 47, 809-813, doi:10.1038/ng.3311.

60. Yalagala, P.C.R.; Sugasini, D.; Dasarathi, S.; Pahan, K.; Subbaiah, P.V. Dietary lysophosphatidylcholine-EPA enriches both EPA and DHA in the brain: potential treatment for depression. J Lipid Res 2019, 60, 566-578, doi:10.1194/jlr.M090464.

61. Patrick, R.P. Role of phosphatidylcholine-DHA in preventing APOE4-associated Alzheimer's disease. FASEB J 2019, 33, 1554-1564, doi:10.1096/fj.201801412R.

62. Dutta-Roy, A.K. Cellular uptake of long-chain fatty acids: role of membrane-associated fatty-acid-binding/transport proteins. Cellular and Molecular Life Sciences 2000, 57, 1360-1372, doi:10.1007/pl00000621.

63. Mitchell, R.W.; On, N.H.; Del Bigio, M.R.; Miller, D.W.; Hatch, G.M. Fatty acid transport protein expression in human brain and potential role in fatty acid transport across human brain microvessel endothelial cells. J Neurochem 2011, 117, 735-746, doi:10.1111/j.1471-4159.2011.07245.x.

64. Wong, B.H.; Silver, D.L. Mfsd2a: A Physiologically Important Lysolipid Transporter in the Brain and Eye. Adv Exp Med Bio/ 2020, 1276, 223-234, doi:10.1007/978-981-15-60828_14.

65. Sanchez-Campillo, M.; Ruiz-Palacios, M.; Ruiz-Alcaraz, A.J.; Prieto-Sanchez, M.T.; Blanco-Carnero, J.E.; Zornoza, M.; Ruiz-Pastor, M.J.; Demmelmair, H.; Sanchez-Solis, M.; Koletzko, B., et al. Child Head Circumference and Placental MFSD2a Expression Are Associated to the Level of MFSD2a in Maternal Blood During Pregnancy. Front Endocrinol (Lausanne) 2020, 11, 38, doi:10.3389/fendo.2020.00038.

66. Thies, F.; Delachambre, M.C.; Bentejac, M.; Lagarde, M.; Lecerf, J. Unsaturated fatty acids esterified in 2-acyl-I-lysophosphatidylcholine bound to albumin are more efficiently 
taken up by the young rat brain than the unesterified form. J Neurochem 1992, 59, 1110-1116, doi:10.1111/j.1471-4159.1992.tb08353.x.

67. Chmurzynska, A. The multigene family of fatty acid-binding proteins (FABPs): function, structure and polymorphism. J App/ Genet 2006, 47, 39-48, doi:10.1007/BF03194597.

68. Owada, Y.; Yoshimoto, T.; Kondo, H. Spatio-temporally differential expression of genes for three members of fatty acid binding proteins in developing and mature rat brains. J Chem Neuroanat 1996, 12, 113-122, doi:10.1016/s0891-0618(96)00192-5.

69. Cataltepe, O.; Arikan, M.C.; Ghelfi, E.; Karaaslan, C.; Ozsurekci, Y.; Dresser, K.; Li, Y.; Smith, T.W.; Cataltepe, S. Fatty acid binding protein 4 is expressed in distinct endothelial and non-endothelial cell populations in glioblastoma. Neuropathol App/ Neurobio/ 2012, 38, 400-410, doi:10.1111/j.1365-2990.2011.01237.x.

70. Feng, L.; Hatten, M.E.; Heintz, N. Brain lipid-binding protein (BLBP): a novel signaling system in the developing mammalian CNS. Neuron 1994, 12, 895-908, doi:10.1016/0896-6273(94)90341-7.

71. Liang, Y.; Bollen, A.W.; Aldape, K.D.; Gupta, N. Nuclear FABP7 immunoreactivity is preferentially expressed in infiltrative glioma and is associated with poor prognosis in EGFR-overexpressing glioblastoma. BMC Cancer2006, 6, 97, doi:10.1186/1471-2407-697.

72. Kaloshi, G.; Mokhtari, K.; Carpentier, C.; Taillibert, S.; Lejeune, J.; Marie, Y.; Delattre, J.Y.; Godbout, R.; Sanson, M. FABP7 expression in glioblastomas: relation to prognosis, invasion and EGFR status. J Neuroonco/ 2007, 84, 245-248, doi:10.1007/s11060-0079377-4.

73. De Rosa, A.; Pellegatta, S.; Rossi, M.; Tunici, P.; Magnoni, L.; Speranza, M.C.; Malusa, F.; Miragliotta, V.; Mori, E.; Finocchiaro, G., et al. A radial glia gene marker, fatty acid 
binding protein 7 (FABP7), is involved in proliferation and invasion of glioblastoma cells. PLoS One 2012, 7, e52113, doi:10.1371/journal.pone.0052113.

74. Liu, R.Z.; Mita, R.; Beaulieu, M.; Gao, Z.; Godbout, R. Fatty acid binding proteins in brain development and disease. Int J Dev Bio/2010, 54, 1229-1239, doi:10.1387/ijdb.092976rl.

75. Bernlohr, D.A.; Coe, N.R.; Simpson, M.A.; Hertzel, A.V. Regulation of gene expression in adipose cells by polyunsaturated fatty acids. Adv Exp Med Biol 1997, 422, 145-156, doi:10.1007/978-1-4757-2670-1_12.

76. Murphy, E.J.; Owada, Y.; Kitanaka, N.; Kondo, H.; Glatz, J.F. Brain arachidonic acid incorporation is decreased in heart fatty acid binding protein gene-ablated mice. Biochemistry 2005, 44, 6350-6360, doi:10.1021/bi047292r.

77. Hanhoff, T.; Lucke, C.; Spener, F. Insights into binding of fatty acids by fatty acid binding proteins. Mol Cell Biochem 2002, 239, 45-54.

78. Balendiran, G.K.; Schnutgen, F.; Scapin, G.; Borchers, T.; Xhong, N.; Lim, K.; Godbout, R.; Spener, F.; Sacchettini, J.C. Crystal structure and thermodynamic analysis of human brain fatty acid-binding protein. J Biol Chem 2000, 275, 27045-27054, doi:10.1074/jbc.M003001200.

79. Owada, Y. Fatty acid binding protein: localization and functional significance in the brain. Tohoku J Exp Med2008, 214, 213-220, doi:10.1620/tjem.214.213.

80. Maximin, E.; Langelier, B.; Aioun, J.; Al-Gubory, K.H.; Bordat, C.; Lavialle, M.; Heberden, C. Fatty acid binding protein 7 and $n-3$ poly unsaturated fatty acid supply in early rat brain development. Dev Neurobio/2016, 76, 287-297, doi:10.1002/dneu.22314.

81. Kawakita, E.; Hashimoto, M.; Shido, O. Docosahexaenoic acid promotes neurogenesis in vitro and in vivo. Neuroscience 2006, 139, 991-997, doi:10.1016/j.neuroscience.2006.01.021. 
82. Sakayori, N.; Maekawa, M.; Numayama-Tsuruta, K.; Katura, T.; Moriya, T.; Osumi, N. Distinctive effects of arachidonic acid and docosahexaenoic acid on neural stem /progenitor cells. Genes Cel/s 2011, 16, 778-790, doi:10.1111/j.1365-2443.2011.01527.x.

83. Cheon, M.S.; Kim, S.H.; Fountoulakis, M.; Lubec, G. Heart type fatty acid binding protein $(\mathrm{H}-\mathrm{FABP})$ is decreased in brains of patients with Down syndrome and Alzheimer's disease. J Neural Transm Supp/ 2003, 10.1007/978-3-7091-6721-2_20, 225-234, doi:10.1007/978-3-7091-6721-2_20.

84. Sanchez-Font, M.F.; Bosch-Comas, A.; Gonzalez-Duarte, R.; Marfany, G. Overexpression of FABP7 in Down syndrome fetal brains is associated with PKNOX1 gene-dosage imbalance. Nucleic Acids Res 2003, 31, 2769-2777, doi:10.1093/nar/gkg396.

85. Watanabe, A.; Toyota, T.; Owada, Y.; Hayashi, T.; Iwayama, Y.; Matsumata, M.; Ishitsuka, Y.; Nakaya, A.; Maekawa, M.; Ohnishi, T., et al. Fabp7 maps to a quantitative trait locus for a schizophrenia endophenotype. PLoS Biol 2007, 5, e297, doi:10.1371/journal.pbio.0050297.

86. Braff, D.L.; Geyer, M.A.; Light, G.A.; Sprock, J.; Perry, W.; Cadenhead, K.S.; Swerdlow, N.R. Impact of prepulse characteristics on the detection of sensorimotor gating deficits in schizophrenia. Schizophr Res 2001, 49, 171-178, doi:10.1016/s0920-9964(00)00139-0.

87. Gearhart, D.A.; Toole, P.F.; Warren Beach, J. Identification of brain proteins that interact with 2-methylnorharman. An analog of the parkinsonian-inducing toxin, MPP+. Neurosci Res 2002, 44, 255-265, doi:10.1016/s0168-0102(02)00133-5.

88. Steinacker, P.; Mollenhauer, B.; Bibl, M.; Cepek, L.; Esselmann, H.; Brechlin, P.; Lewczuk, P.; Poser, S.; Kretzschmar, H.A.; Wiltfang, J., et al. Heart fatty acid binding protein as a potential diagnostic marker for neurodegenerative diseases. Neurosci Lett 2004, 370, 36-39, doi:10.1016/j.neulet.2004.07.061. 
89. Cunnane, S.C.; Plourde, M.; Pifferi, F.; Begin, M.; Feart, C.; Barberger-Gateau, P. Fish, docosahexaenoic acid and Alzheimer's disease. Prog Lipid Res 2009, 48, 239-256, doi:10.1016/j.plipres.2009.04.001.

90. Calderon, F.; Kim, H.Y. Docosahexaenoic acid promotes neurite growth in hippocampal neurons. Journal of Neurochemistry 2004, 10.1111/j.1471-4159.2004.02520.x, doi:10.1111/j.1471-4159.2004.02520.x.

91. Cao, D.; Xue, R.; Xu, J.; Liu, Z. Effects of docosahexaenoic acid on the survival and neurite outgrowth of rat cortical neurons in primary cultures. Journal of Nutritional Biochemistry 2005, 10.1016/j.jnutbio.2005.02.002, doi:10.1016/j.jnutbio.2005.02.002.

92. Kawakita, E.; Hashimoto, M.; Shido, O. Docosahexaenoic acid promotes neurogenesis in vitro and in vivo. Neuroscience 2006, 10.1016/j.neuroscience.2006.01.021, doi:10.1016/j.neuroscience.2006.01.021.

93. Insua, M.F.; Garelli, A.; Rotstein, N.P.; German, O.L.; Arias, A.; Politi, L.E. Cell cycle regulation in retinal progenitors by glia-derived neurotrophic factor and docosahexaenoic acid. Investigative Ophthalmology and Visual Science 2003, 10.1167/iovs.02-0952, doi:10.1167/iovs.02-0952.

94. Aïd, S.; Vancassel, S.; Poumès-Ballihaut, C.; Chalon, S.; Guesnet, P.; Lavialle, M. Effect of a diet-induced n-3 PUFA depletion on cholinergic parameters in the rat hippocampus. Journal of Lipid Research 2003, 10.1194/jlr.m300079-jlr200, doi:10.1194/jlr.m300079jlr200.

95. Chalon, S. Omega-3 fatty acids and monoamine neurotransmission. Prostaglandins Leukotrienes and Essential Fatty Acids 2006, 10.1016/j.plefa.2006.07.005, doi:10.1016/j.plefa.2006.07.005. 
96. Innis, S.M. Essential fatty acids in growth and development. In Progress in Lipid Research, 1991.

97. Anderson, G.J.; Neuringer, M.; Lin, D.S.; Connor, W.E. Can prenatal N-3 fatty acid deficiency be completely reversed after birth? Effects on retinal and brain biochemistry and visual function in rhesus monkeys. Pediatric Research 2005, 10.1203/01.pdr.0000182188.31596.5a LK -, doi:10.1203/01.pdr.0000182188.31596.5a LK -.

98. Calderon, F.; Kim, H.Y. Docosahexaenoic acid promotes neurite growth in hippocampal neurons. J Neurochem 2004, 90, 979-988, doi:10.1111/j.1471-4159.2004.02520.x.

99. Innis, S.M. Dietary (n-3) Fatty Acids and Brain Development. The Journal of Nutrition 2018, 10.1093/jn/137.4.855, doi:10.1093/jn/137.4.855.

100. Coti Bertrand, P.; O'Kusky, J.R.; Innis, S.M. Maternal dietary (n-3) fatty acid deficiency alters neurogenesis in the embryonic rat brain. The Journal of nutrition 2006, 10.1093/jn/136.6.1570, doi:10.1093/jn/136.6.1570.

101. Salem, N.; Litman, B.; Kim, H.Y.; Gawrisch, K. Mechanisms of action of docosahexaenoic acid in the nervous system. Lipids 2001, 10.1007/s11745-001-0805-6, doi:10.1007/s11745-001-0805-6.

102. Lengqvist, J.; Mata de Urquiza, A.; Bergman, A.-C.; Willson, T.M.; Sjövall, J.; Perlmann, T.; Griffiths, W.J. Polyunsaturated Fatty Acids Including Docosahexaenoic and Arachidonic Acid Bind to the Retinoid X Receptor $\alpha$ Ligand-binding Domain. Molecular \& Cellular Proteomics 2004, 10.1074/mcp.M400003-MCP200， doi:10.1074/mcp.M400003MCP200. 
103. Rioux, L.; Arnold, S.E. The expression of retinoic acid receptor alpha is increased in the granule cells of the dentate gyrus in schizophrenia. Psychiatry Research 2005, 10.1016/j.psychres.2004.11.003, doi:10.1016/j.psychres.2004.11.003.

104. Wada, K.; Nakajima, A.; Katayama, K.; Kudo, C.; Shibuya, A.; Kubota, N.; Terauchi, Y.; Tachibana, M.; Miyoshi, H.; Kamisaki, Y., et al. Peroxisome proliferator-activated receptor $\gamma$-mediated regulation of neural stem cell proliferation and differentiation. Journal of Biological Chemistry 2006, 10.1074/jbc.M513786200, doi:10.1074/jbc.M513786200.

105. Cao, D.H.; Xu, J.F.; Xue, R.H.; Zheng, W.F.; Liu, Z.L. Protective effect of chronic ethyl docosahexaenoate administration on brain injury in ischemic gerbils. Pharmacology Biochemistry and Behavior 2004, 10.1016/j.pbb.2004.09.016, doi:10.1016/j.pbb.2004.09.016.

106. Green, P.; Glozman, S.; Weiner, L.; Yavin, E. Enhanced free radical scavenging and decreased lipid peroxidation in the rat fetal brain after treatment with ethyl docosahexaenoate. Biochimica et Biophysica Acta - Molecular and Cell Biology of Lipids 2001, 10.1016/S1388-1981(01)00132-9, doi:10.1016/S1388-1981(01)00132-9.

107. Okada, M.; Amamoto, T.; Tomonaga, M.; Kawachi, A.; Yazawa, K.; Mine, K.; Fujiwara, M. The chronic administration of docosahexaenoic acid reduces the spatial cognitive deficit following transient forebrain ischemia in rats. Neuroscience 1996, 10.1016/03064522(95)00427-0, doi:10.1016/0306-4522(95)00427-0.

108. Samson, F.P.; Fabunmi, T.E.; Patrick, A.T.; Jee, D.; Gutsaeva, D.R.; Jahng, W.J. Fatty Acid Composition and Stoichiometry Determine the Angiogenesis Microenvironment. ACS Omega 2021, 6, 5953-5961, doi:10.1021/acsomega.1c00196. 
109. Richardson, A.J.; Burton, J.R.; Sewell, R.P.; Spreckelsen, T.F.; Montgomery, P. Docosahexaenoic acid for reading, cognition and behavior in children aged 7-9 years: a randomized, controlled trial (the DOLAB Study). PLoS One 2012, 7, e43909, doi:10.1371/journal.pone.0043909.

110. Meldrum, S.J.; D'Vaz, N.; Simmer, K.; Dunstan, J.A.; Hird, K.; Prescott, S.L. Effects of highdose fish oil supplementation during early infancy on neurodevelopment and language: a randomised controlled trial. $B r$ J Nutr 2012, 108, 1443-1454, doi:10.1017/S0007114511006878.

111. Wang, W.; Shinto, L.; Connor, W.E.; Quinn, J.F. Nutritional biomarkers in Alzheimer's disease: the association between carotenoids, n-3 fatty acids, and dementia severity. $J$ Alzheimers Dis 2008, 13, 31-38, doi:10.3233/jad-2008-13103.

112. Cao, L.; Tan, L.; Wang, H.F.; Jiang, T.; Zhu, X.C.; Lu, H.; Tan, M.S.; Yu, J.T. Dietary Patterns and Risk of Dementia: a Systematic Review and Meta-Analysis of Cohort Studies. Mol Neurobio/2016, 53, 6144-6154, doi:10.1007/s12035-015-9516-4.

113. Bousquet, M.; Saint-Pierre, M.; Julien, C.; Salem, N., Jr.; Cicchetti, F.; Calon, F. Beneficial effects of dietary omega-3 polyunsaturated fatty acid on toxin-induced neuronal degeneration in an animal model of Parkinson's disease. FASEB J 2008, 22, 1213-1225, doi:10.1096/fj.07-9677com.

114. Sinn, N.; Milte, C.M.; Street, S.J.; Buckley, J.D.; Coates, A.M.; Petkov, J.; Howe, P.R. Effects of n-3 fatty acids, EPA v. DHA, on depressive symptoms, quality of life, memory and executive function in older adults with mild cognitive impairment: a 6-month randomised controlled trial. Br J Nutr 2012, 107, 1682-1693, doi:10.1017/S0007114511004788. 
115. Freund-Levi, Y.; Eriksdotter-Jonhagen, M.; Cederholm, T.; Basun, H.; Faxen-Irving, G.; Garlind, A.; Vedin, I.; Vessby, B.; Wahlund, L.O.; Palmblad, J. Omega-3 fatty acid treatment in 174 patients with mild to moderate Alzheimer disease: OmegAD study: a randomized double-blind trial. Arch Neurol 2006, 63, 1402-1408, doi:10.1001/archneur.63.10.1402.

116. Quinn, J.F.; Raman, R.; Thomas, R.G.; Yurko-Mauro, K.; Nelson, E.B.; Van Dyck, C.; Galvin, J.E.; Emond, J.; Jack, C.R., Jr.; Weiner, M., et al. Docosahexaenoic acid supplementation and cognitive decline in Alzheimer disease: a randomized trial. JAMA 2010, 304, 19031911, doi:10.1001/jama.2010.1510.

117. Eilander, A.; Hundscheid, D.C.; Osendarp, S.J.; Transler, C.; Zock, P.L. Effects of n-3 long chain polyunsaturated fatty acid supplementation on visual and cognitive development throughout childhood: a review of human studies. Prostaglandins Leukot Essent Fatty Acids 2007, 76, 189-203, doi:10.1016/j.plefa.2007.01.003.

118. Oh, D.Y.; Walenta, E.; Akiyama, T.E.; Lagakos, W.S.; Lackey, D.; Pessentheiner, A.R.; Sasik, R.; Hah, N.; Chi, T.J.; Cox, J.M., et al. A Gpr120-selective agonist improves insulin resistance and chronic inflammation in obese mice. Nature Medicine 2014, 10.1038/nm.3614, doi:10.1038/nm.3614.

119. Chitre, N.M.; Wood, B.J.; Ray, A.; Moniri, N.H.; Murnane, K.S. Docosahexaenoic acid protects motor function and increases dopamine synthesis in a rat model of Parkinson's disease via mechanisms associated with increased protein kinase activity in the striatum. Neuropharmacology 2020, 167, 107976, doi:10.1016/j.neuropharm.2020.107976.

120. Diep, Q.N.; Touyz, R.M.; Schiffrin, E.L. Docosahexaenoic acid, a peroxisome proliferatoractivated receptor- $\alpha$ ligand, induces apoptosis in vascular smooth muscle cells by 
stimulation of p38: Mitogen-activated protein kinase. Hypertension 2000, 10.1161/01.HYP.36.5.851, doi:10.1161/01.HYP.36.5.851.

121. Zúñiga, J.; Cancino, M.; Medina, F.; Varela, P.; Vargas, R.; Tapia, G.; Videla, L.A.; Fernández, V. N-3 PUFA supplementation triggers PPAR- $\alpha$ activation and PPAR- $\alpha / N F-\kappa B$ interaction: Anti-inflammatory implications in liver ischemia-reperfusion injury. PLoS ONE 2011, 6, doi:10.1371/journal.pone.0028502.

122. Anderson, E.; Taylor, D. Stressing the heart of the matter: re-thinking the mechanisms underlying therapeutic effects of $\mathrm{n}-3$ polyunsaturated fatty acids. F1000 Medicine Reports 2012, 10.3410/m4-13, doi:10.3410/m4-13.

123. Robertson, R.; Guihéneuf, F.; Stengel, D.B.; Fitzgerald, G.; Ross, P.; Stanton, C. AlgaeDerived Polyunsaturated Fatty Acids : Implications for Human Health. In Polyunsaturated fatty acids sources, antioxidant properties and health Benefits, 2013.

124. Kuda, O. Bioactive metabolites of docosahexaenoic acid. In Biochimie, 2017.

125. Westphal, C.; Konkel, A.; Schunck, W.H. CYP-eicosanoids - A new link between omega3 fatty acids and cardiac disease? In Prostaglandins and Other Lipid Mediators, 2011.

126. Duvall, M.G.; Levy, B.D. DHA- and EPA-derived resolvins, protectins, and maresins in airway inflammation. European Journal of Pharmacology 2016, 10.1016/j.ejphar.2015.11.001, doi:10.1016/j.ejphar.2015.11.001.

127. Serhan, C.N. Pro-resolving lipid mediators are leads for resolution physiology. In Nature, 2014.

128. Bisicchia, E.; Sasso, V.; Catanzaro, G.; Leuti, A.; Besharat, Z.M.; Chiacchiarini, M.; Molinari, M.; Ferretti, E.; Viscomi, M.T.; Chiurchiù, V. Resolvin D1 Halts Remote Neuroinflammation and Improves Functional Recovery after Focal Brain Damage Via 
ALX/FPR2 Receptor-Regulated MicroRNAs. Molecular Neurobiology 2018, 55, 68946905, doi:10.1007/s12035-018-0889-z.

129. Recchiuti, A.; Krishnamoorthy, S.; Fredman, G.; Chiang, N.; Serhan, C.N. MicroRNAs in resolution of acute inflammation: identification of novel resolvin D1-miRNA circuits. The FASEB Journa/2010, 10.1096/fj.10-169599, doi:10.1096/fj.10-169599.

130. Zuo, G.; Zhang, D.; Mu, R.; Shen, H.; Li, X.; Wang, Z.; Li, H.; Chen, G. Resolvin D2 protects against cerebral ischemia/reperfusion injury in rats. Molecular Brain 2018, 11, 1-13, doi:10.1186/s13041-018-0351-1.

131. Dalli, J.; Winkler, J.W.; Colas, R.A.; Arnardottir, H.; Cheng, C.Y.C.; Chiang, N.; Petasis, N.A.; Serhan, C.N. Resolvin D3 and aspirin-triggered resolvin D3 are potent immunoresolvents. Chemistry and Biology 2013, 10.1016/j.chembiol.2012.11.010, doi:10.1016/j.chembiol.2012.11.010.

132. Hong, S.; Tjonahen, E.; Morgan, E.L.; Lu, Y.; Serhan, C.N.; Rowley, A.F. Rainbow trout (Oncorhynchus mykiss) brain cells biosynthesize novel docosahexaenoic acid-derived resolvins and protectins - Mediator lipidomic analysis. Prostaglandins and Other Lipid Mediators 2005, 10.1016/j.prostaglandins.2005.04.004, doi:10.1016/j.prostaglandins.2005.04.004.

133. Ariel, A.; Serhan, C.N. New lives given by cell death: Macrophage differentiation following their encounter with apoptotic leukocytes during the resolution of inflammation. In Frontiers in Immunology, 2012.

134. Stables, M.J.; Shah, S.; Camon, E.B.; Lovering, R.C.; Newson, J.; Bystrom, J.; Farrow, S.; Gilroy, D.W. Transcriptomic analyses of murine resolution-phase macrophages. Blood 2011, 10.1182/blood-2011-04-345330, doi:10.1182/blood-2011-04-345330. 
135. Zhang, M.J.; Spite, M. Resolvins: Anti-Inflammatory and Proresolving Mediators Derived from Omega-3 Polyunsaturated Fatty Acids. Annual Review of Nutrition 2012, 10.1146/annurev-nutr-071811-150726, doi:10.1146/annurev-nutr-071811-150726.

136. Serhan, C.N.; Dalli, J.; Colas, R.A.; Winkler, J.W.; Chiang, N. Protectins and maresins: New pro-resolving families of mediators in acute inflammation and resolution bioactive metabolome. In Biochimica et Biophysica Acta - Molecular and Cell Biology of Lipids, 2015.

137. Serhan, C.N.; Dalli, J.; Karamnov, S.; Choi, A.; Park, C.-K.; Xu, Z.-Z.; Ji, R.-R.; Zhu, M.; Petasis, N.A. Macrophage proresolving mediator maresin 1 stimulates tissue regeneration and controls pain. The FASEB Journa/2012, 10.1096/fj.11-201442, doi:10.1096/fj.11-201442.

138. Serhan, C.N.; Yang, R.; Martinod, K.; Kasuga, K.; Pillai, P.S.; Porter, T.F.; Oh, S.F.; Spite, M. Maresins: novel macrophage mediators with potent antiinflammatory and proresolving actions. The Journal of Experimental Medicine 2008, 10.1084/jem.20081880, doi:10.1084/jem.20081880.

139. Yanes, O.; Clark, J.; Wong, D.M.; Patti, G.J.; Sánchez-Ruiz, A.; Benton, H.P.; Trauger, S.A.; Desponts, C.; Ding, S.; Siuzdak, G. Metabolic oxidation regulates embryonic stem cell differentiation. Nature Chemical Biology 2010, 10.1038/nchembio.364, doi:10.1038/nchembio.364.

140. Yang, T.; Xu, G.; Newton, P.T.; Chagin, A.S.; Mkrtchian, S.; Carlström, M.; Zhang, X.M.; Harris, R.A.; Cooter, M.; Berger, M., et al. Maresin 1 attenuates neuroinflammation in a mouse model of perioperative neurocognitive disorders. British Journal of Anaesthesia 2019, 10.1016/j.bja.2018.10.062, doi:10.1016/j.bja.2018.10.062.

141. Francos-Quijorna, I.; Santos-Nogueira, E.; Gronert, K.; Sullivan, A.B.; Kopp, M.A.; Brommer, B.; David, S.; Schwab, J.M.; López-Vales, R. Maresin 1 Promotes Inflammatory 
Resolution, Neuroprotection, and Functional Neurological Recovery After Spinal Cord Injury. The Journal of Neuroscience 2017, 10.1523/jneurosci.1395-17.2017, doi:10.1523/jneurosci.1395-17.2017.

142. Chiang, N.; Libreros, S.; Norris, P.C.; de la Rosa, X.; Serhan, C.N. Maresin 1 activates LGR6 receptor promoting phagocyte immunoresolvent functions. J Clin Invest 2019, 129, 5294-5311, doi:10.1172/JCl129448.

143. Bazan, N.G.; Molina, M.F.; Gordon, W.C. Docosahexaenoic Acid Signalolipidomics in Nutrition: Significance in Aging, Neuroinflammation, Macular Degeneration, Alzheimer's, and Other Neurodegenerative Diseases. Annual Review of Nutrition 2011, 10.1146/annurev.nutr.012809.104635, doi:10.1146/annurev.nutr.012809.104635.

144. Balas, L.; Durand, T. Dihydroxylated E,E,Z-docosatrienes. An overview of their synthesis and biological significance. Progress in Lipid Research 2016, 10.1016/j.plipres.2015.10.002, doi:10.1016/j.plipres.2015.10.002.

145. Bazan, N.G. Neuroprotectin D1 (NPD1): a DHA-derived mediator that protects brain and retina against cell injury-induced oxidative stress. Brain pathology (Zurich, Switzerland) 2005.

146. Calandria, J.M.; Marcheselli, V.L.; Mukherjee, P.K.; Uddin, J.; Winkler, J.W.; Petasis, N.A.; Bazan, N.G. Selective survival rescue in 15-lipoxygenase-1-deficient retinal pigment epithelial cells by the novel docosahexaenoic acid-derived mediator, neuroprotectin D1. Journal of Biological Chemistry 2009, 10.1074/jbc.M109.003988, doi:10.1074/jbc.M109.003988.

147. García-Sastre, A. XLessons from lipids in the fight against influenza. In Cell, 2013.

148. Morita, M.; Kuba, K.; Ichikawa, A.; Nakayama, M.; Katahira, J.; Iwamoto, R.; Watanebe, T.; Sakabe, S.; Daidoji, T.; Nakamura, S., et al. The lipid mediator protectin D1 inhibits 
influenza virus replication and improves severe influenza. Cell 2013, 10.1016/j.cell.2013.02.027, doi:10.1016/j.cell.2013.02.027.

149. Zhao, Y.; Calon, F.; Julien, C.; Winkler, J.W.; Petasis, N.A.; Lukiw, W.J.; Bazan, N.G. Docosahexaenoic acid-derived neuroprotectin D1 induces neuronal survival via secretase- and PPARy-mediated mechanisms in Alzheimer's disease models. PLOS ONE 2011, 10.1371/journal.pone.0015816, doi:10.1371/journal.pone.0015816.

150. Dyall, S.C. Long-chain omega-3 fatty acids and the brain: A review of the independent and shared effects of EPA, DPA and DHA. In Frontiers in Aging Neuroscience, 2015.

151. Gladine, C.; Laurie, J.-C.; Giulia, C.; Dominique, B.; Corinne, C.; Nathalie, H.; Bart, S.; Giuseppe, Z.; Alessio, P.; Jean-Marie, G., et al. Neuroprostanes, produced by free-radical mediated peroxidation of DHA, inhibit the inflammatory response of human macrophages. Free Radical Biology and Medicine 2014, 10.1016/j.freeradbiomed.2014.10.590, doi:10.1016/j.freeradbiomed.2014.10.590.

152. Groeger, A.L.; Cipollina, C.; Cole, M.P.; Woodcock, S.R.; Bonacci, G.; Rudolph, T.K.; Rudolph, V.; Freeman, B.A.; Schopfer, F.J. Cyclooxygenase-2 generates antiinflammatory mediators from omega-3 fatty acids. Nature Chemical Biology 2010, 10.1038/nchembio.367, doi:10.1038/nchembio.367.

153. De Petrocellis, L.; Melck, D.; Bisogno, T.; Milone, A.; Di Marzo, V. Finding of the endocannabinoid signalling system in Hydra, a very primitive organism: Possible role in the feeding response. Neuroscience 1999, 10.1016/S0306-4522(98)00749-0, doi:10.1016/S0306-4522(98)00749-0.

154. Kim, J.; Carlson, M.E.; Watkins, B.A. Docosahexaenoyl ethanolamide improves glucose uptake and alters endocannabinoid system gene expression in proliferating and 
differentiating C2C12 myoblasts. Frontiers in Physiology 2014, 10.3389/fphys.2014.00100, doi:10.3389/fphys.2014.00100.

155. Piazza, P.V.; Lafontan, M.; Girard, J. Integrated physiology and pathophysiology of CB1mediated effects of the endocannabinoid system. In Diabetes and Metabolism, 2007.

156. Soderstrom, K. Endocannabinoids Link Feeding State and Auditory Perception-Related Gene Expression. Journal of Neuroscience 2004, 10.1523/jneurosci.3298-04.2004, doi:10.1523/jneurosci.3298-04.2004.

157. Valenti, M.; Cottone, E.; Martinez, R.; De Pedro, N.; Rubio, M.; Viveros, M.P.; Franzoni, M.F.; Delgado, M.J.; Di Marzo, V. The endocannabinoid system in the brain of Carassius auratus and its possible role in the control of food intake. Journal of Neurochemistry 2005, 10.1111/j.1471-4159.2005.03406.x, doi:10.1111/j.1471-4159.2005.03406.x.

158. Watanabe, S.; Doshi, M.; Hamazaki, T. n-3 Polyunsaturated fatty acid (PUFA) deficiency elevates and n-3 PUFA enrichment reduces brain 2-arachidonoylglycerol level in mice. Prostaglandins Leukotrienes and Essential Fatty Acids 2003, 10.1016/S09523278(03)00056-5, doi:10.1016/S0952-3278(03)00056-5.

159. Masoodi, M.; Kuda, O.; Rossmeisl, M.; Flachs, P.; Kopecky, J. Lipid signaling in adipose tissue: Connecting inflammation \& metabolism. In Biochimica et Biophysica Acta Molecular and Cell Biology of Lipids, 2015.

160. D'Addario, C.; Micioni Di Bonaventura, M.V.; Pucci, M.; Romano, A.; Gaetani, S.; Ciccocioppo, R.; Cifani, C.; Maccarrone, M. Endocannabinoid signaling and food addiction. In Neuroscience and Biobehavioral Reviews, 2014.

161. Wagner, J.J.; Alger, B.E. Increased neuronal excitability during depolarization-induced suppression of inhibition in rat hippocampus. Journal of Physiology 1996, 10.1113/jphysiol.1996.sp021577, doi:10.1113/jphysiol.1996.sp021577. 
162. Wilson, R.I.; Nicoll, R.A. Neuroscience: Endocannabinoid signaling in the brain. In Science, 2002.

163. Calder, P.C. Omega-3 polyunsaturated fatty acids and inflammatory processes: Nutrition or pharmacology? British Journal of Clinical Pharmacology 2013, 10.1111/j.1365-2125.2012.04374.x, doi:10.1111/j.1365-2125.2012.04374.x.

164. Lu, H.C.; MacKie, K. An introduction to the endogenous cannabinoid system. In Biological Psychiatry, 2016.

165. Jacobs, B.L.; Van Praag, H.; Gage, F.H. Adult brain neurogenesis and psychiatry: A novel theory of depression. In Molecular Psychiatry, 2000.

166. McEwen, B.S. Stress, sex, and neural adaptation to a changing environment: Mechanisms of neuronal remodeling. Annals of the New York Academy of Sciences 2010, 10.1111/j.1749-6632.2010.05568.x, doi:10.1111/j.1749-6632.2010.05568.x.

167. Lupien, S.J.; McEwen, B.S.; Gunnar, M.R.; Heim, C. Effects of stress throughout the lifespan on the brain, behaviour and cognition. In Nature Reviews Neuroscience, 2009.

168. Ranabir, S.; Reetu, K. Stress and hormones. Indian Journal of Endocrinology and Metabolism 2011, 10.4103/2230-8210.77573, doi:10.4103/2230-8210.77573.

169. Laugero, K.D.; Smilowitz, J.T.; German, J.B.; Jarcho, M.R.; Mendoza, S.P.; Bales, K.L. Plasma omega 3 polyunsaturated fatty acid status and monounsaturated fatty acids are altered by chronic social stress and predict endocrine responses to acute stress in titi monkeys. Prostaglandins Leukotrienes and Essential Fatty Acids 2011, 10.1016/j.plefa.2010.12.003, doi:10.1016/j.plefa.2010.12.003.

170. O'Brien, J.S.; Sampson, E.L. Lipid composition of the normal human brain: gray matter, white matter, and myelin. Journal of lipid research 1965. 
171. Song, C.; Manku, M.S.; Horrobin, D.F. Long-Chain Polyunsaturated Fatty Acids Modulate Interleukin-1 $\beta$-Induced Changes in Behavior, Monoaminergic Neurotransmitters, and Brain Inflammation in Rats. The Journal of Nutrition 2018, 10.1093/jn/138.5.954, doi:10.1093/jn/138.5.954.

172. Bozzatello, P.; Brignolo, E.; De Grandi, E.; Bellino, S. Supplementation with Omega-3 Fatty Acids in Psychiatric Disorders: A Review of Literature Data. Journal of Clinical Medicine 2016, 10.3390/jcm5080067, doi:10.3390/jcm5080067.

173. Hibbeln, J.R. Fish consumption and major depression [9]. In Lancet, 1998.

174. Van Gelder, B.M.; Tijhuis, M.; Kalmijn, S.; Kromhout, D. Fish consumption, n-3 fatty acids, and subsequent 5-y cognitive decline in elderly men: The Zutphen Elderly Study. American Journal of Clinical Nutrition 2007.

175. Schaefer, E.J.; Bongard, V.; Beiser, A.S.; Lamon-Fava, S.; Robins, S.J.; Au, R.; Tucker, K.L.; Kyle, D.J.; Wilson, P.W.F.; Wolf, P.A. Plasma phosphatidylcholine docosahexaenoic acid content and risk of dementia and alzheimer disease: The framingham heart study. Archives of Neurology 2006, 10.1001/archneur.63.11.1545, doi:10.1001/archneur.63.11.1545.

176. Holmes, C. Inflammation in Alzheimer's disease. In Dementia, Fifth Edition, 2017; $10.1201 / 9781315381572$.

177. Trépanier, M.O.; Hopperton, K.E.; Orr, S.K.; Bazinet, R.P. N-3 polyunsaturated fatty acids in animal models with neuroinflammation: An update. European Journal of Pharmacology 2016, 10.1016/j.ejphar.2015.05.045, doi:10.1016/j.ejphar.2015.05.045.

178. Lukiw, W.J.; Cui, J.G.; Marcheselli, V.L.; Bodker, M.; Botkjaer, A.; Gotlinger, K.; Serhan, C.N.; Bazan, N.G. A role for docosahexaenoic acid-derived neuroprotectin D1 in neural cell 
survival and Alzheimer disease. Journal of Clinical Investigation 2005, 10.1172/JCI25420, doi:10.1172/JCI25420.

179. Boudrault, C.; Bazinet, R.P.; Ma, D.W.L. Experimental models and mechanisms underlying the protective effects of $n-3$ polyunsaturated fatty acids in Alzheimer's disease. In Journal of Nutritional Biochemistry, 2009.

180. Hashimoto, M.; Hossain, S.; Agdul, H.; Shido, O. Docosahexaenoic acid-induced amelioration on impairment of memory learning in amyloid $\beta$-infused rats relates to the decreases of amyloid $\beta$ and cholesterol levels in detergent-insoluble membrane fractions. Biochimica et Biophysica Acta - Molecular and Cell Biology of Lipids 2005, 10.1016/j.bbalip.2005.11.011, doi:10.1016/j.bbalip.2005.11.011.

181. Seidl, S.E.; Santiago, J.A.; Bilyk, H.; Potashkin, J.A. The emerging role of nutrition in Parkinson's disease. In Frontiers in Aging Neuroscience, 2014.

182. Kiliaan, A.; Königs, A. Critical appraisal of omega-3 fatty acids in attentiondeficit/hyperactivity disorder treatment. Neuropsychiatric Disease and Treatment 2016, Volume 12, 1869-1882, doi:10.2147/ndt.s68652.

183. Weiser, M.J.; Butt, C.M.; Mohajeri, M.H. Docosahexaenoic acid and cognition throughout the lifespan. In Nutrients, 2016.

184. Grossfield, A.; Feller, S.E.; Pitman, M.C. A role for direct interactions in the modulation of rhodopsin by -3 polyunsaturated lipids. Proceedings of the National Academy of Sciences 2006, 10.1073/pnas.0508352103, doi:10.1073/pnas.0508352103.

185. Stillwell, W.; Shaikh, S.R.; Zerouga, M.; Siddiqui, R.; Wassall, S.R. Docosahexaenoic acid affects cell signaling by altering lipid rafts. Reproduction Nutrition Development 2005, 10.1051/rnd:2005046, doi:10.1051/rnd:2005046. 
186. Bazan, N.G. Cell survival matters: docosahexaenoic acid signaling, neuroprotection and photoreceptors. In Trends in Neurosciences, 2006.

187. Kitajka, K.; Puskas, L.G.; Zvara, A.; Hackler, L.; Barcelo-Coblijn, G.; Yeo, Y.K.; Farkas, T. The role of $n-3$ polyunsaturated fatty acids in brain: Modulation of rat brain gene expression by dietary n-3 fatty acids. Proceedings of the National Academy of Sciences 2002, 10.1073/pnas.042698699, doi:10.1073/pnas.042698699.

188. Vreugdenhil, M.; Bruehl, C.; Voskuyl, R.A.; Kang, J.X.; Leaf, A.; Wadman, W.J. Polyunsaturated fatty acids modulate sodium and calcium currents in CA1 neurons. Proceedings of the National Academy of Sciences 2002, 10.1073/pnas.93.22.12559, doi:10.1073/pnas.93.22.12559.

189. Mita, R.; Beaulieu, M.J.; Field, C.; Godbout, R. Brain Fatty Acid-binding Protein and $\omega-$ 3/w-6 Fatty Acids. Journal of Biological Chemistry 2010, 285, 37005-37015, doi:10.1074/jbc.m110.170076.

190. Boucher, O.; Burden, M.J.; Muckle, G.; Saint-Amour, D.; Ayotte, P.; Dewailly, E.; Nelson, C.A.; Jacobson, S.W.; Jacobson, J.L. Neurophysiologic and neurobehavioral evidence of beneficial effects of prenatal omega-3 fatty acid intake on memory function at school age. Am J Clin Nutr2011, 93, 1025-1037, doi:10.3945/ajcn.110.000323.

191. McNamara, R.K. DHA Deficiency and Prefrontal Cortex Neuropathology in Recurrent Affective Disorders. The Journal of Nutrition 2010, 10.3945/jn.109.113233, doi:10.3945/jn.109.113233.

192. McNamara, R.K.; Hahn, C.G.; Jandacek, R.; Rider, T.; Tso, P.; Stanford, K.E.; Richtand, N.M. Selective Deficits in the Omega-3 Fatty Acid Docosahexaenoic Acid in the Postmortem Orbitofrontal Cortex of Patients with Major Depressive Disorder. Biological Psychiatry 2007, 10.1016/j.biopsych.2006.08.026, doi:10.1016/j.biopsych.2006.08.026. 
193. Basak, S.; Vilasagaram, S.; Duttaroy, A.K. Maternal dietary deficiency of $n-3$ fatty acids affects metabolic and epigenetic phenotypes of the developing fetus. Prostaglandins Leukot Essent Fatty Acids 2020, 158, 102109, doi:10.1016/j.plefa.2020.102109.

194. Srinivas, V., Molangiri, A., Mallepogu A., Kona S.R., Ibrahim, A, Duttaroy, A.K., Basak, S. . Maternal n-3 PUFA deficiency alters uterine artery remodeling and placental epigenome in the mice. Journal of Nutritional Biochemistry 2021, In the press.

195. Mulder, K.A.; King, D.J.; Innis, S.M. Omega-3 fatty acid deficiency in infants before birth identified using a randomized trial of maternal DHA supplementation in pregnancy. PLOS ONE 2014, 10.1371/journal.pone.0083764, doi:10.1371/journal.pone.0083764.

196. Bos, D.J.; Oranje, B.; Veerhoek, E.S.; Van Diepen, R.M.; Weusten, J.M.H.; Demmelmair, H.; Koletzko, B.; De Sain-Van Der Velden, M.G.M.; Eilander, A.; Hoeksma, M., et al. Reduced Symptoms of Inattention after Dietary Omega-3 Fatty Acid Supplementation in Boys with and without Attention Deficit/Hyperactivity Disorder. Neuropsychopharmacology 2015, 40, 2298-2306, doi:10.1038/npp.2015.73.

197. Parellada, M.; Llorente, C.; Calvo, R.; Gutierrez, S.; Lázaro, L.; Graell, M.; Guisasola, M.; Dorado, M.L.; Boada, L.; Romo, J., et al. Randomized trial of omega-3 for autism spectrum disorders: Effect on cell membrane composition and behavior. European Neuropsychopharmacology 2017, 10.1016/j.euroneuro.2017.08.426, doi:10.1016/j.euroneuro.2017.08.426.

198. Bauer, I.; Hughes, M.; Rowsell, R.; Cockerell, R.; Pipingas, A.; Crewther, S.; Crewther, D. Omega-3 supplementation improves cognition and modifies brain activation in young adults. Human Psychopharmacology 2014, 10.1002/hup.2379, doi:10.1002/hup.2379.

199. Jaremka, L.M.; Derry, H.M.; Bornstein, R.; Prakash, R.S.; Peng, J.; Belury, M.A.; Andridge, R.R.; Malarkey, W.B.; Kiecolt-Glaser, J.K. Omega-3 supplementation and loneliness- 
related memory problems: Secondary analyses of a randomized controlled trial. Psychosomatic Medicine 2014, 10.1097/PSY.0000000000000104, doi:10.1097/PSY.0000000000000104.

200. Smith, S.L.; Rouse, C.A. Docosahexaenoic acid and the preterm infant. Maternal Health, Neonatology and Perinatology 2017, 10.1186/s40748-017-0061-1, doi:10.1186/s40748-017-0061-1.

201. Albanese, E.; Dangour, A.D.; Uauy, R.; Acosta, D.; Guerra, M.; Guerra, S.S.; Huang, Y.; Jacob, K.S.; de Rodriguez, J.L.; Noriega, L.H., et al. Dietary fish and meat intake and dementia in Latin America, China, and India: a 10/66 Dementia Research Group population-based study. Am J Clin Nutr 2009, 90, 392-400, doi:10.3945/ajen.2009.27580.

202. Milte, C.M.; Sinn, N.; Street, S.J.; Buckley, J.D.; Coates, A.M.; Howe, P.R. Erythrocyte polyunsaturated fatty acid status, memory, cognition and mood in older adults with mild cognitive impairment and healthy controls. Prostaglandins Leukot Essent Fatty Acids 2011, 84, 153-161, doi:10.1016/j.plefa.2011.02.002.

203. Yin, Y.; Fan, Y.; Lin, F.; Xu, Y.; Zhang, J. Nutrient biomarkers and vascular risk factors in subtypes of mild cognitive impairment: a cross-sectional study. J Nutr Health Aging 2015, 19, 39-47, doi:10.1007/s12603-014-0510-8.

204. Bazinet, R.P.; Layé, S. Polyunsaturated fatty acids and their metabolites in brain function and disease. In Nature Reviews Neuroscience, 2014.

205. Shamim, A.; Mahmood, T.; Ahsan, F.; Kumar, A.; Bagga, P. Lipids: An insight into the neurodegenerative disorders. In Clinical Nutrition Experimental, 2018.

206. Lopez, L.B.; Kritz-Silverstein, D.; Barrett Connor, E. High dietary and plasma levels of the omega-3 fatty acid docosahexaenoic acid are associated with decreased dementia risk: 
the Rancho Bernardo study. J Nutr Health Aging 2011, 15, 25-31, doi:10.1007/s12603011-0009-5.

207. Phillips, M.A.; Childs, C.E.; Calder, P.C.; Rogers, P.J. Lower omega-3 fatty acid intake and status are associated with poorer cognitive function in older age: A comparison of individuals with and without cognitive impairment and Alzheimer's disease. Nutr Neurosci2012, 15, 271-277, doi:10.1179/1476830512Y.0000000026.

208. Schaefer, E.J.; Bongard, V.; Beiser, A.S.; Lamon-Fava, S.; Robins, S.J.; Au, R.; Tucker, K.L.; Kyle, D.J.; Wilson, P.W.; Wolf, P.A. Plasma phosphatidylcholine docosahexaenoic acid content and risk of dementia and Alzheimer disease: the Framingham Heart Study. Arch Neuro/2006, 63, 1545-1550, doi:10.1001/archneur.63.11.1545.

209. Shatenstein, B.; Kergoat, M.J.; Reid, I. Poor nutrient intakes during 1-year follow-up with community-dwelling older adults with early-stage Alzheimer dementia compared to cognitively intact matched controls. J Am Diet Assoc 2007, 107, 2091-2099, doi:10.1016/j.jada.2007.09.008.

210. Kotani, S.; Sakaguchi, E.; Warashina, S.; Matsukawa, N.; Ishikura, Y.; Kiso, Y.; Sakakibara, M.; Yoshimoto, T.; Guo, J.; Yamashima, T. Dietary supplementation of arachidonic and docosahexaenoic acids improves cognitive dysfunction. Neurosci Res 2006, 56, 159 164, doi:10.1016/j.neures.2006.06.010.

211. Wurtman, R.J.; Ulus, I.H.; Cansev, M.; Watkins, C.J.; Wang, L.; Marzloff, G. Synaptic proteins and phospholipids are increased in gerbil brain by administering uridine plus docosahexaenoic acid orally. Brain Res 2006, 1088, 83-92, doi:10.1016/j.brainres.2006.03.019.

212. Gomez-Soler, M.; Cordobilla, B.; Morato, X.; Fernandez-Duenas, V.; Domingo, J.C.; Ciruela, F. Triglyceride Form of Docosahexaenoic Acid Mediates Neuroprotection in 
Experimental Parkinsonism. Front Neurosci 2018, 12, 604, doi:10.3389/fnins.2018.00604.

213. Patrick, R.P.; Ames, B.N. Vitamin D and the omega-3 fatty acids control serotonin synthesis and action, part 2: relevance for ADHD, bipolar disorder, schizophrenia, and impulsive behavior. FASEB J 2015, 29, 2207-2222, doi:10.1096/fj.14-268342.

214. McNamara, R.K.; Jandacek, R.; Rider, T.; Tso, P.; Hahn, C.G.; Richtand, N.M.; Stanford, K.E. Abnormalities in the fatty acid composition of the postmortem orbitofrontal cortex of schizophrenic patients: gender differences and partial normalization with antipsychotic medications. Schizophr Res 2007, 91, 37-50, doi:10.1016/j.schres.2006.11.027.

215. Sinn, N.; Bryan, J. Effect of supplementation with polyunsaturated fatty acids and micronutrients on learning and behavior problems associated with child ADHD. J Dev Behav Pediatr 2007, 28, 82-91, doi:10.1097/01.DBP.0000267558.88457.a5.

216. Sinn, N.; Bryan, J.; Wilson, C. Cognitive effects of polyunsaturated fatty acids in children with attention deficit hyperactivity disorder symptoms: a randomised controlled trial. Prostaglandins Leukot Essent Fatty Acids 2008, 78, 311-326, doi:10.1016/j.plefa.2008.04.004.

217. Belanger, S.A.; Vanasse, M.; Spahis, S.; Sylvestre, M.P.; Lippe, S.; L'Heureux, F.; Ghadirian, P.; Vanasse, C.M.; Levy, E. Omega-3 fatty acid treatment of children with attentiondeficit hyperactivity disorder: A randomized, double-blind, placebo-controlled study. Paediatr Child Health 2009, 14, 89-98, doi:10.1093/pch/14.2.89.

218. Johnson, M.; Ostlund, S.; Fransson, G.; Kadesjo, B.; Gillberg, C. Omega-3/omega-6 fatty acids for attention deficit hyperactivity disorder: a randomized placebo-controlled trial in children and adolescents. J Atten Disord 2009, 12, 394-401, doi:10.1177/1087054708316261. 
219. Gustafsson, P.A.; Birberg-Thornberg, U.; Duchen, K.; Landgren, M.; Malmberg, K.; Pelling, H.; Strandvik, B.; Karlsson, T. EPA supplementation improves teacher-rated behaviour and oppositional symptoms in children with ADHD. Acta Paediatr2010, 99, 1540-1549, doi:10.1111/j.1651-2227.2010.01871.x.

220. Hariri, M.; Djazayery, A.; Djalali, M.; Saedisomeolia, A.; Rahimi, A.; Abdolahian, E. Effect of $n-3$ supplementation on hyperactivity, oxidative stress and inflammatory mediators in children with attention-deficit-hyperactivity disorder. Malays J Nutr 2012, 18, 329335.

221. Behdani, F.; Hebrani, P.; Naseraee, A.; Haghighi, M.B.; Akhavanrezayat, A. Does omega3 supplement enhance the therapeutic results of methylphenidate in attention deficit hyperactivity disorder patients? J Res Med Sci2013, 18, 653-658.

222. Dashti, N.; Hekmat, H.; Soltani, H.R.; Rahimdel, A.; Javaherchian, M. Comparison of therapeutic effects of omega-3 and methylphenidate (ritalin((R))) in treating children with attention deficit hyperactivity disorder. Iran J Psychiatry Behav Sci 2014, 8, 7-11.

223. Bos, D.J.; Oranje, B.; Veerhoek, E.S.; Van Diepen, R.M.; Weusten, J.M.; Demmelmair, H.; Koletzko, B.; de Sain-van der Velden, M.G.; Eilander, A.; Hoeksma, M., et al. Reduced Symptoms of Inattention after Dietary Omega-3 Fatty Acid Supplementation in Boys with and without Attention Deficit/Hyperactivity Disorder. Neuropsychopharmacology 2015, 40, 2298-2306, doi:10.1038/npp.2015.73.

224. Anand, P.; Sachdeva, A. Effect of Poly Unsaturated Fatty Acids Administration on Children with Attention Deficit Hyperactivity Disorder: A Randomized Controlled Trial. J Clin Diagn Res 2016, 10, OC01-OC05, doi:10.7860/JCDR/2016/20423.8471. 
225. Assareh, M.; Davari Ashtiani, R.; Khademi, M.; Jazayeri, S.; Rai, A.; Nikoo, M. Efficacy of Polyunsaturated Fatty Acids (PUFA) in the Treatment of Attention Deficit Hyperactivity Disorder. J Atten Disord 2017, 21, 78-85, doi:10.1177/1087054712463962.

226. Kean, J.D.; Sarris, J.; Scholey, A.; Silberstein, R.; Downey, L.A.; Stough, C. Reduced inattention and hyperactivity and improved cognition after marine oil extract (PCSO524(R)) supplementation in children and adolescents with clinical and subclinical symptoms of attention-deficit hyperactivity disorder (ADHD): a randomised, doubleblind, placebo-controlled trial. Psychopharmacology (Berl) 2017, 234, 403-420, doi:10.1007/s00213-016-4471-y.

227. Voigt, R.G.; Llorente, A.M.; Jensen, C.L.; Fraley, J.K.; Berretta, M.C.; Heird, W.C. A randomized, double-blind, placebo-controlled trial of docosahexaenoic acid supplementation in children with attention-deficit/hyperactivity disorder. J Pediatr 2001, 139, 189-196, doi:10.1067/mpd.2001.116050.

228. Amminger, G.P.; Schafer, M.R.; Papageorgiou, K.; Klier, C.M.; Cotton, S.M.; Harrigan, S.M.; Mackinnon, A.; McGorry, P.D.; Berger, G.E. Long-chain omega-3 fatty acids for indicated prevention of psychotic disorders: a randomized, placebo-controlled trial. Arch Gen Psychiatry 2010, 67, 146-154, doi:10.1001/archgenpsychiatry.2009.192.

229. Pawelczyk, T.; Grancow-Grabka, M.; Kotlicka-Antczak, M.; Trafalska, E.; Pawelczyk, A. A randomized controlled study of the efficacy of six-month supplementation with concentrated fish oil rich in omega-3 polyunsaturated fatty acids in first episode schizophrenia. J Psychiatr Res 2016, 73, 34-44, doi:10.1016/j.jpsychires.2015.11.013.

230. Ammann, E.M.; Pottala, J.V.; Harris, W.S.; Espeland, M.A.; Wallace, R.; Denburg, N.L.; Carnahan, R.M.; Robinson, J.G. omega-3 fatty acids and domain-specific cognitive 
aging: secondary analyses of data from WHISCA. Neurology 2013, 81, 1484-1491, doi:10.1212/WNL.0b013e3182a9584c.

231. Maekawa, M.; Watanabe, A.; Iwayama, Y.; Kimura, T.; Hamazaki, K.; Balan, S.; Ohba, H.; Hisano, Y.; Nozaki, Y.; Ohnishi, T., et al. Polyunsaturated fatty acid deficiency during neurodevelopment in mice models the prodromal state of schizophrenia through epigenetic changes in nuclear receptor genes. Trans/ Psychiatry 2017, 7, e1229, doi:10.1038/tp.2017.182.

232. McNamara, R.K.; Jandacek, R.; Tso, P.; Blom, T.J.; Welge, J.A.; Strawn, J.R.; Adler, C.M.; Strakowski, S.M.; DelBello, M.P. Adolescents with or at ultra-high risk for bipolar disorder exhibit erythrocyte docosahexaenoic acid and eicosapentaenoic acid deficits: a candidate prodromal risk biomarker. Early Interv Psychiatry 2016, 10, 203-211, doi:10.1111/eip.12282.

233. Stoll, A.L.; Severus, W.E.; Freeman, M.P.; Rueter, S.; Zboyan, H.A.; Diamond, E.; Cress, K.K.; Marangell, L.B. Omega 3 fatty acids in bipolar disorder: a preliminary double-blind, placebo-controlled trial. Arch Gen Psychiatry 1999, 56, 407-412, doi:10.1001/archpsyc.56.5.407.

234. Chiu, C.C.; Huang, S.Y.; Chen, C.C.; Su, K.P. Omega-3 fatty acids are more beneficial in the depressive phase than in the manic phase in patients with bipolar I disorder. $J$ Clin Psychiatry 2005, 66, 1613-1614, doi:10.4088/jcp.v66n1219b.

235. Clayton, E.H.; Hanstock, T.L.; Hirneth, S.J.; Kable, C.J.; Garg, M.L.; Hazell, P.L. Reduced mania and depression in juvenile bipolar disorder associated with long-chain omega-3 polyunsaturated fatty acid supplementation. Eur J Clin Nutr 2009, 63, 1037-1040, doi:10.1038/ejcn.2008.81. 
236. Birch, E.E.; Garfield, S.; Castaneda, Y.; Hughbanks-Wheaton, D.; Uauy, R.; Hoffman, D. Visual acuity and cognitive outcomes at 4 years of age in a double-blind, randomized trial of long-chain polyunsaturated fatty acid-supplemented infant formula. Early Hum Dev 2007, 83, 279-284, doi:10.1016/j.earlhumdev.2006.11.003.

237. Osendarp, S.J.; Baghurst, K.I.; Bryan, J.; Calvaresi, E.; Hughes, D.; Hussaini, M.; Karyadi, S.J.; van Klinken, B.J.; van der Knaap, H.C.; Lukito, W., et al. Effect of a 12-mo micronutrient intervention on learning and memory in well-nourished and marginally nourished school-aged children: 2 parallel, randomized, placebo-controlled studies in Australia and Indonesia. Am J Clin Nutr 2007, 86, 1082-1093, doi:10.1093/ajcn/86.4.1082.

238. Dalton, A.; Wolmarans, P.; Witthuhn, R.C.; van Stuijvenberg, M.E.; Swanevelder, S.A.; Smuts, C.M. A randomised control trial in schoolchildren showed improvement in cognitive function after consuming a bread spread, containing fish flour from a marine source. Prostaglandins Leukot Essent Fatty Acids 2009, 80, 143-149, doi:10.1016/j.plefa.2008.12.006.

239. Brew, B.K.; Toelle, B.G.; Webb, K.L.; Almqvist, C.; Marks, G.B.; investigators, C. Omega-3 supplementation during the first 5 years of life and later academic performance: a randomised controlled trial. Eur J Clin Nutr 2015, 69, 419-424, doi:10.1038/ejcn.2014.155.

240. Lassek, W.D.; Gaulin, S.J. Sex differences in the relationship of dietary Fatty acids to cognitive measures in american children. Front Evol Neurosci 2011, 3, 5, doi:10.3389/fnevo.2011.00005.

241. Shulkin, M.; Pimpin, L.; Bellinger, D.; Kranz, S.; Fawzi, W.; Duggan, C.; Mozaffarian, D. N3 fatty acid supplementation in mothers, preterm infants, and term infants and 
childhood psychomotor and visual development: A systematic review and metaanalysis. Journal of Nutrition 2018, 10.1093/jn/nxx031, doi:10.1093/jn/nxx031.

242. Basak, S.; Duttaroy, A.K. Effects of fatty acids on angiogenic activity in the placental extravillious trophoblast cells. Prostaglandins Leukot Essent Fatty Acids 2013, 88, 155 162, doi:10.1016/j.plefa.2012.10.001.

243. Contreras, M.A.; Greiner, R.S.; Chang, M.C.; Myers, C.S.; Salem, N., Jr.; Rapoport, S.I. Nutritional deprivation of alpha-linolenic acid decreases but does not abolish turnover and availability of unacylated docosahexaenoic acid and docosahexaenoyl-CoA in rat brain. J Neurochem 2000, 75, 2392-2400, doi:10.1046/j.1471-4159.2000.0752392.x.

244. Coronary heart disease in seven countries. Summary. Circulation 1970, 41, I186-195.

245. Sun, G.Y.; Shelat, P.B.; Jensen, M.B.; He, Y.; Sun, A.Y.; Simonyi, A. Phospholipases A2 and inflammatory responses in the central nervous system. Neuromolecular Med 2010, 12, 133-148, doi:10.1007/s12017-009-8092-z.

246. Bazinet, R.P. Is the brain arachidonic acid cascade a common target of drugs used to manage bipolar disorder? Biochem Soc Trans 2009, 37, 1104-1109, doi:10.1042/BST0371104.

247. Rapoport, S.I. Arachidonic acid and the brain. I Nutr 2008, 138, 2515-2520, doi:10.1093/jn/138.12.2515.

248. Duncan, R.E.; Bazinet, R.P. Brain arachidonic acid uptake and turnover: implications for signaling and bipolar disorder. Curr Opin Clin Nutr Metab Care 2010, 13, 130-138, doi:10.1097/MCO.0b013e328336b615.

249. Fraser, T.; Tayler, H.; Love, S. Fatty acid composition of frontal, temporal and parietal neocortex in the normal human brain and in Alzheimer's disease. Neurochem Res 2010, 35, 503-513, doi:10.1007/s11064-009-0087-5. 
250. Kriem, B.; Sponne, I.; Fifre, A.; Malaplate-Armand, C.; Lozac'h-Pillot, K.; Koziel, V.; YenPotin, F.T.; Bihain, B.; Oster, T.; Olivier, J.L., et al. Cytosolic phospholipase A2 mediates neuronal apoptosis induced by soluble oligomers of the amyloid-beta peptide. FASEB J2005, 19, 85-87, doi:10.1096/fj.04-1807fje.

251. Sanchez-Mejia, R.O.; Newman, J.W.; Toh, S.; Yu, G.Q.; Zhou, Y.; Halabisky, B.; Cisse, M.; Scearce-Levie, K.; Cheng, I.H.; Gan, L., et al. Phospholipase A2 reduction ameliorates cognitive deficits in a mouse model of Alzheimer's disease. Nat Neurosci 2008, 11, 1311-1318, doi:10.1038/nn.2213.

252. Desbene, C.; Malaplate-Armand, C.; Youssef, I.; Garcia, P.; Stenger, C.; Sauvee, M.; Fischer, N.; Rimet, D.; Koziel, V.; Escanye, M.C., et al. Critical role of cPLA2 in Abeta oligomer-induced neurodegeneration and memory deficit. Neurobiol Aging 2012, 33, 1123 e1117-1129, doi:10.1016/j.neurobiolaging.2011.11.008.

253. Hosono, T.; Mouri, A.; Nishitsuji, K.; Jung, C.G.; Kontani, M.; Tokuda, H.; Kawashima, H.; Shibata, H.; Suzuki, T.; Nabehsima, T., et al. Arachidonic or Docosahexaenoic Acid Diet Prevents Memory Impairment in Tg2576 Mice. J Alzheimers Dis 2015, 48, 149-162, doi:10.3233/JAD-150341.

254. Yasojima, K.; Schwab, C.; McGeer, E.G.; McGeer, P.L. Distribution of cyclooxygenase-1 and cyclooxygenase-2 mRNAs and proteins in human brain and peripheral organs. Brain Res 1999, 830, 226-236, doi:10.1016/s0006-8993(99)01389-x.

255. Mohri, I.; Kadoyama, K.; Kanekiyo, T.; Sato, Y.; Kagitani-Shimono, K.; Saito, Y.; Suzuki, K.; Kudo, T.; Takeda, M.; Urade, Y., et al. Hematopoietic prostaglandin D synthase and DP1 receptor are selectively upregulated in microglia and astrocytes within senile plaques from human patients and in a mouse model of Alzheimer disease. J Neuropatho/ Exp Neuro/2007, 66, 469-480, doi:10.1097/01.jnen.0000240472.43038.27. 
256. McGahon, B.; Clements, M.P.; Lynch, M.A. The ability of aged rats to sustain long-term potentiation is restored when the age-related decrease in membrane arachidonic acid concentration is reversed. Neuroscience 1997, 81, 9-16, doi:10.1016/s03064522(97)00116-4.

257. Angelova, P.R.; Muller, W.S. Arachidonic acid potently inhibits both postsynaptic-type Kv4.2 and presynaptic-type Kv1.4 IA potassium channels. EurJ Neurosci2009, 29, $1943-$ 1950, doi:10.1111/j.1460-9568.2009.06737.x.

258. Connell, E.; Darios, F.; Broersen, K.; Gatsby, N.; Peak-Chew, S.Y.; Rickman, C.; Davletov, B. Mechanism of arachidonic acid action on syntaxin-Munc18. EMBO Rep 2007, 8, 414419, doi:10.1038/sj.embor.7400935.

259. Boneva, N.B.; Kikuchi, M.; Minabe, Y.; Yamashima, T. Neuroprotective and ameliorative actions of polyunsaturated fatty acids against neuronal diseases: implication of fatty acid-binding proteins (FABP) and G protein-coupled receptor 40 (GPR40) in adult neurogenesis. J Pharmaco/ Sci 2011, 116, 163-172, doi:10.1254/jphs.10r34fm.

260. Pan, Y.; Scanlon, M.J.; Owada, Y.; Yamamoto, Y.; Porter, C.J.; Nicolazzo, J.A. Fatty AcidBinding Protein 5 Facilitates the Blood-Brain Barrier Transport of Docosahexaenoic Acid. Mol Pharm 2015, 12, 4375-4385, doi:10.1021/acs.molpharmaceut.5b00580.

261. Marszalek, J.R.; Kitidis, C.; Dirusso, C.C.; Lodish, H.F. Long-chain acyl-CoA synthetase 6 preferentially promotes DHA metabolism. J Biol Chem 2005, 280, 10817-10826, doi:10.1074/jbc.M411750200.

262. Green, J.T.; Orr, S.K.; Bazinet, R.P. The emerging role of group VI calcium-independent phospholipase A2 in releasing docosahexaenoic acid from brain phospholipids. J Lipid Res 2008, 49, 939-944, doi:10.1194/jlr.R700017-JLR200. 
263. Luo, C.L.; Li, Q.Q.; Chen, X.P.; Zhang, X.M.; Li, L.L.; Li, B.X.; Zhao, Z.Q.; Tao, L.Y. Lipoxin A4 attenuates brain damage and downregulates the production of pro-inflammatory cytokines and phosphorylated mitogen-activated protein kinases in a mouse model of traumatic brain injury. Brain research 2013, 1502, 1-10, doi:10.1016/j.brainres.2013.01.037.

264. Pamplona, F.A.; Ferreira, J.; Menezes de Lima, O., Jr.; Duarte, F.S.; Bento, A.F.; Forner, S.; Villarinho, J.G.; Bellocchio, L.; Wotjak, C.T.; Lerner, R., et al. Anti-inflammatory lipoxin A4 is an endogenous allosteric enhancer of CB1 cannabinoid receptor. Proc Natl Acad Sci U S A 2012, 109, 21134-21139, doi:10.1073/pnas.1202906109.

265. Qawasmi, A.; Landeros-Weisenberger, A.; Leckman, J.F.; Bloch, M.H. Meta-analysis of Long-Chain Polyunsaturated Fatty Acid Supplementation of Formula and Infant Cognition. PEDIATR/CS 2012, 10.1542/peds.2011-2127, doi:10.1542/peds.2011-2127.

266. Simmer, K.; Patole, S.K.; Rao, S.C. Long-chain polyunsaturated fatty acid supplementation in infants born at term. The Cochrane database of systematic reviews 2011, 10.1002/14651858.CD000376.pub3, doi:10.1002/14651858.CD000376.pub3.

267. Smithers, L.G.; Gibson, R.A.; McPhee, A.; Makrides, M. Effect of long-chain polyunsaturated fatty acid supplementation of preterm infants on disease risk and neurodevelopment: A systematic review of randomized controlled trials. American Journal of Clinical Nutrition 2008.

268. Lauritzen, L.; Fewtrell, M.; Agostoni, C. Dietary arachidonic acid in perinatal nutrition: a commentary. Pediatr Res 2015, 77, 263-269, doi:10.1038/pr.2014.166.

269. Carlson, S.E.; Werkman, S.H.; Peeples, J.M.; Cooke, R.J.; Tolley, E.A. Arachidonic acid status correlates with first year growth in preterm infants. Proc Nat/ Acad Sci USA 1993, 90, 1073-1077, doi:10.1073/pnas.90.3.1073. 
270. Alshweki, A.; Muñuzuri, A.P.; Baña, A.M.; de Castro, M.J.; Andrade, F.; Aldamiz-Echevarría, L.; de Pipaón, M.S.; Fraga, J.M.; Couce, M.L. Effects of different arachidonic acid supplementation on psychomotor development in very preterm infants; a randomized controlled trial. Nutr J2015, 14, 101, doi:10.1186/s12937-015-0091-3.

271. Crawford, M.A.; Costeloe, K.; Ghebremeskel, K.; Phylactos, A.; Skirvin, L.; Stacey, F. Are deficits of arachidonic and docosahexaenoic acids responsible for the neural and vascular complications of preterm babies? Am. J. Clin. Nutr. 1997, 66, 1032S-1041S, doi:10.1093/ajen/66.4.1032S.

272. Colombo, J.; Shaddy, D.J.; Gustafson, K.; Gajewski, B.J.; Thodosoff, J.M.; Kerling, E.; Carlson, S.E. The Kansas University DHA Outcomes Study (KUDOS) clinical trial: longterm behavioral follow-up of the effects of prenatal DHA supplementation. The American Journal of Clinical Nutrition 2019, 10.1093/ajcn/nqz018, doi:10.1093/ajcn/nqz018.

273. Keim, S.A.; Boone, K.M.; Klebanoff, M.A.; Turner, A.N.; Rausch, J.; Nelin, M.A.; Rogers, L.K.; Yeates, K.O.; Nelin, L.; Sheppard, K.W. Effect of Docosahexaenoic Add Supplementation vs Placebo on

Developmental Outcomes of Toddlers Born Preterm A Randomized Clinical

Trial. JAMA PEDIATRICS 2018, 10.1001/jamapediatrics.2018.3082, doi:10.1001/jamapediatrics.2018.3082.

274. Makrides, M.; Gibson, R.A.; McPhee, A.J.; Yelland, L.; Quinlivan, J.; Ryan, P.; Doyle, L.W.; Anderson, P.; Else, P.L.; Meyer, B.J., et al. Effect of DHA supplementation during pregnancy on maternal depression and neurodevelopment of young children: A randomized controlled trial. JAMA - Journal of the American Medical Association 2010, 10.1001/jama.2010.1507, doi:10.1001/jama.2010.1507. 
275. Collins, C.T.; Gibson, R.A.; Anderson, P.J.; McPhee, A.J.; Sullivan, T.R.; Gould, J.F.; Ryan, P.; Doyle, L.W.; Davis, P.G.; McMichael, J.E., et al. Neurodevelopmental outcomes at 7 years' corrected age in preterm infants who were fed high-dose docosahexaenoic acid to term equivalent: A follow-up of a randomised controlled trial. BMJ Open 2015, 10.1136/bmjopen-2014-007314, doi:10.1136/bmjopen-2014-007314.

276. Smithers, L.G.; Collins, C.T.; Simmonds, L.A.; Gibson, R.A.; McPhee, A.; Makrides, M. Feeding preterm infants milk with a higher dose of docosahexaenoic acid than that used in current practice does not influence language or behavior in early childhood: A follow-up study of a randomized controlled trial. American Journal of Clinical Nutrition 2010, 10.3945/ajcn.2009.28603, doi:10.3945/ajcn.2009.28603. 